\section{Probiotics: defenders of gastrointestinal habitats}

\author{
Desh D. Singh, ${ }^{1}$ Sarika Amdekar, ${ }^{2}$ \\ Vinod Singh ${ }^{2}$ \\ 'Department of Microbiology, Chhatrapati \\ Shahuji Maharaj Medical University, \\ Chowk, Lucknow; ${ }^{2}$ Department of \\ Microbiology, Barkatullah University, \\ Bhopal, India
}

\section{Abstract}

Intestinal microbiota play an important role in maintaining normal gastrointestinal (GI) function and ensuring that changes in the composition of the intestinal microbiota can promote GI function. The digestive tract is full of bacteria and many of these, including probiotics, are necessary for optimal digestive function. During bacterial gastroenteritis, harmful bacteria invade the digestive tract causing unpleasant symptoms and upsetting the balance between good and bad bacteria. Supplemental probiotics can help restore this balance. Studies have demonstrated that probiotics can often help reduce the severity of symptoms such as diarrhea and may help accelerate recovery. Probiotics are therapeutic preparations of live microorganisms administered in sufficient dosage to be beneficial to health. The therapeutic effects of these microorganisms appear to be strain specific. Primal Defense ${ }^{\circledR}$, a unique, probiotic, bacterial compound, contains probiotics that support gut flora balance, promote consistent bowel function, control stomach acid levels to quickly eliminate burning sensation in the stomach and maintain immune system response. The probiotics in Primal Defense ${ }^{\circledR}$ maximize the benefits of a healthy diet by supporting normal absorption and assimilation of nutrients in the gut. Nearly $75 \%$ of our immune defenses are located in the digestive tract, so maintaining a favorable bacterial balance in the intestines (ideally $80 \%$ good or neutral bacteria to $20 \%$ bad or harmful bacteria) is crucial to achieving and maintaining optimum health.

\section{Introduction}

The mucosa and the lumen of the mammalian gastrointestinal tract harbor complex communities of bacteria. These enteric microorganisms, often referred to as the indigenous or normal microbiota, belong to approximately 1000 species, the population size and distribu- tion of which is variable along the gastrointestinal tract. ${ }^{1}$ Although the host has evolved various tolerogenic mechanisms to promote a stable and productive co-existence with its enteric microbiota, it remains highly responsive to enteropathogens. This ability of the intestine to discriminate between its indigenous microbiota represents a pivotal feature of efficient tolerance and homeostatic mechanisms. ${ }^{2}$

Inflammatory bowel diseases (IBD), including ulcerative colitis (UC) and Crohn's disease (CD), are spontaneously relapsing, immunologically mediated disorders of the intestinal tract. ${ }^{3}$ Homeostasis (tolerance) versus chronic intestinal inflammation is determined by either a regulated or an uncontrolled response of the host to the constant antigenic drive of enteric bacteria. ${ }^{4}$ In the genetically susceptible host, an ineffective mucosal barrier function, and the lack of appropriate mechanisms to terminate mucosal immune responses (loss of immunological tolerance) result in continuous stimulation of the mucosal immune system, leading to chronic inflammation. ${ }^{5}$

Although numerous studies have detailed the cell-mediated mucosal immune response in various animal models of chronic intestinal inflammation and in human IBD, very little is known about the molecular mechanisms of bacteria-specific crosstalk at the mucosal surfaces with respect to the development of chronic intestinal inflammation in the genetically susceptible host. ${ }^{6}$ In the present review, after describing the key players in innate and adaptative immune responses in the intestine, we focus on new insights into mechanisms underlying host-bacteria interaction in the context of intestinal inflammation. ${ }^{7}$

\section{Gastroenteritis}

Gastric inflammation is a constant finding in patients infected with $H$. pylori and represents the host immune response to the organism. From a histological point of view, $H$. pylori-associated chronic gastritis is characterized by surface epithelial degeneration, infiltration of the mucosa by chronic inflammatory cells (lymphocytes, plasma cells, and occasional eosinophils), and a characteristic but variable active component consisting of neutrophils. ${ }^{8}$ Qualitative or quantitative differences in $H$. pylori-induced gastric mucosal inflammation may play a pivotal role in determining the varied clinical outcomes of infection. ${ }^{9}$ This review focuses on the interactions between the organism and host cells which lead to mucosal inflammation.
Correspondence: Vinod Singh, Department of Microbiology, Barkatullah University, Bhopal (M.P) 462026 India.

E-mail: vinodsingh63@yahoo.co.in

Key words: probiotics, diarrohea, IBS, gut immunity.

Conflict of interests: the authors report no conflict of interests.

Received for publication: 28 September 2011 Revision received: 24 August 2012.

Accepted for publication: 11 September 2012.

This work is licensed under a Creative Commons Attribution NonCommercial 3.0 License (CC BYNC 3.0).

CCopyright D.D. Singhet al., 2012

Licensee PAGEPress, Italy

Gastroenterology Insights 2012; 4:e22

doi:10.4081/gi.2012.e22

\section{Colonization}

The protective and immune barrier of the human gastrointestinal (GI) tract has various characteristics. $^{10}$ It includes the epithelial layer, the mucous layer, the mechanics of peristalsis and desquamation, and secretory Immunoglobulin A (IgA) action, all of which have an impact on bacterial attachment. After attachment, colonic bacteria are prevented from mixing with the host's eukaryotic cells by the epithelial layer, which acts as a vital barrier to invasion. ${ }^{11}$ The barrier's healthy structure and proper functioning are essential for the health of the human host. In these complex systems, the delicate balance between the gastrointestinal tract and the microflora is cooperatively maintained (Figure 1). ${ }^{12}$

The GI tract is sterile until an infant ingests vaginal and fecal microflora during delivery. The population of microflora in the infant GI tract is further enhanced by feeding. ${ }^{13}$ The breast-fed infant contains a colon population of $90 \%$ Bifidobacteria with some Enterobacteriaceace and Enterococci present, but virtually no Bacteroides, Staphylococci, Lactobacilli, or Clostridia. ${ }^{14}$ In contrast, Bifidobacteria do not predominate in the bottle-fed infant. Breast-fed infants switched to cow's milk or solid foods colonize Bifidobacteria, Clostridia, Lactobacilli, Bacteroides, Streptococci, and enterics. ${ }^{15}$ The type and number of indigenous microflora increase distally along the length of the gastrointestinal tract. The upper GI tract has relatively fewer bacteria secondary to saliva production and increased intestinal motility, which effectively move bacteria along the 
intestine and prevent large numbers from adhering to mucosal surfaces. ${ }^{16}$ In addition, gastric acid suppresses growth in the stomach. The relatively sparse flora of the upper intestine generally numbers less than $\left(10^{5}\right)$ colony forming units (cfu) per milliliter (mL) of contents, until the mid ileum where the population increases to $10^{7} \mathrm{cfu} / \mathrm{mL}$ of contents, indicating a shift toward the flora that heavily populates the colon. Favorable characteristics found in probiotics colonizing the human gut are exhibited by Lactobacillus plantarum, $L$. rhamnosus, $L$. reuteri, and $L$. agilis. ${ }^{17}$ There are several species of Lactobacilli and Bifidobacteria within this milieu possessing complex enzymes and functions that can potentially either benefit or harm the health of the host. ${ }^{18}$ Alterations in the gastrointestinal barrier or in the composition of the microflora of the gut provide an opportunity for resultant malfunction and disease. For instance, overgrowth of one bacterial species can upset the ecosystem of the gut and result in derangement of beneficial characteristics (Figure 2). ${ }^{19}$

Overgrowth of one bacterial species or imbalances in microflora resulting from a disturbed mucosal layer can alter digestive function, intestinal products, and/or immunological function. ${ }^{20}$ In addition, a defective epithelial layer can allow bacteria to gain entry into the human host. This breach can arouse an inflammatory response in the host that has the potential to further alter normal function. ${ }^{21}$

Colonization of the gut with appropriate microflora contributes to its ability to function

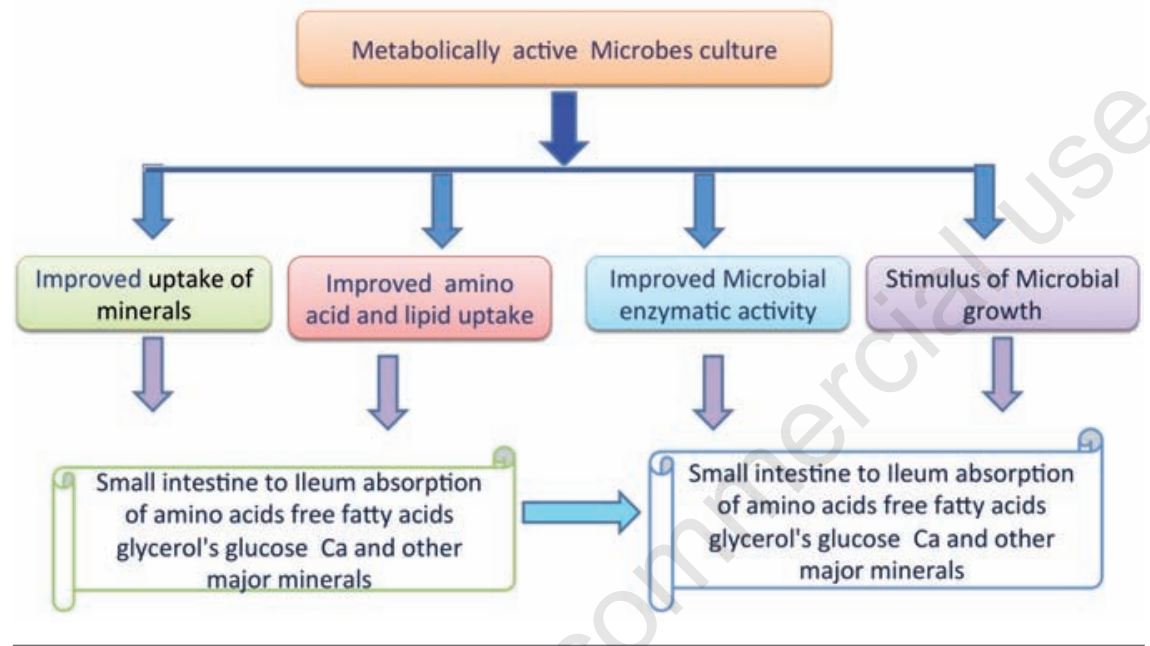

Figure 1. Metabolically active microbes culture.

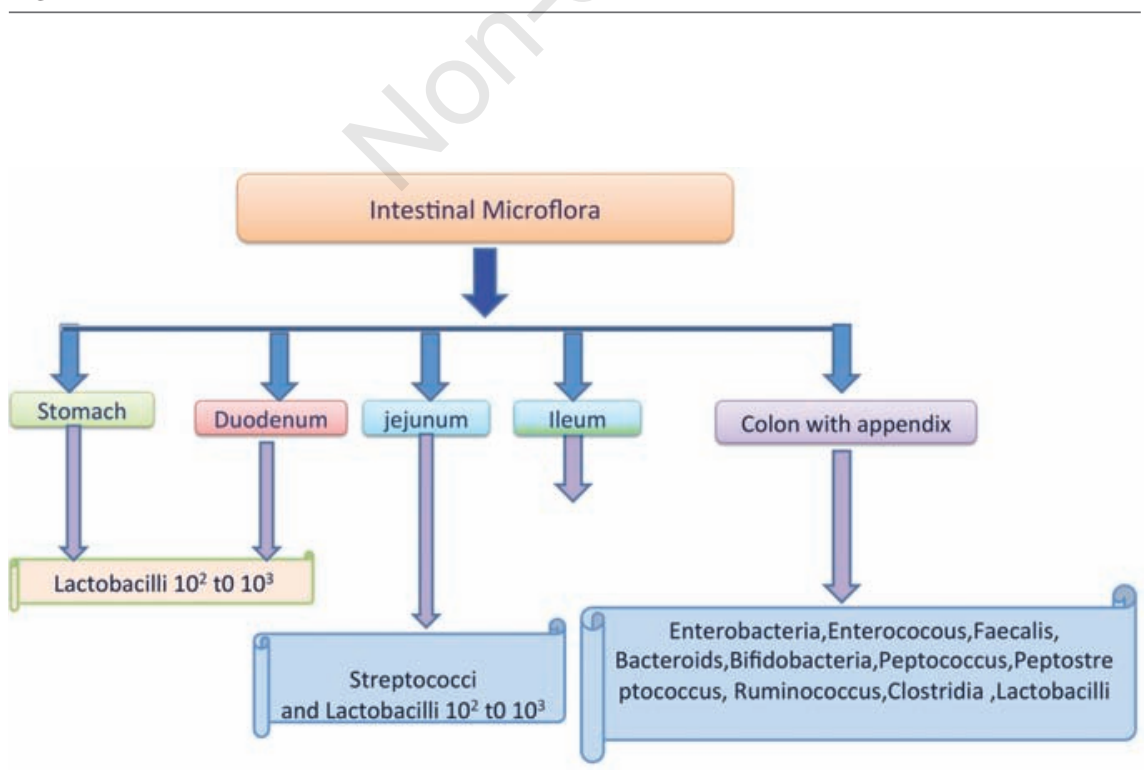

Figure 2. Metabolically active microbes. normally. Commensal microflora byproducts contribute to the health of the intestinal tract and include short-chain fatty acids (SCFAs), polyamines, vitamins, antioxidants, and amino acids. ${ }^{22}$ For example, the SCFA butyric acid, derived from carbohydrate fermentation, provides the main fuel for colonocytes in the large intestine. In addition, Lactobacillus species can prevent food decay, preserve antioxidants and vitamins, remove toxic food components, and prevent pathogenesis of Entero-bacteriaceae, $S$. aureus, and Enterococci found in fermented foods. ${ }^{23}$

Probiotics modulate not only the endogenous flora of the GI tract but also the immune system. Lactobacilli augment both cellular and humoral immunity. ${ }^{24}$ Lactic acid-producing bacteria stimulate various aspects of the immune system, including phagocytic function of macrophages, natural killer cells, monocytes, and neutrophils. Clearly, interaction of commensal gastrointestinal flora with the gutassociated immune system is an important key to maintaining normal immune function. ${ }^{25}$

\section{Enzymatic digestion}

All metabolic processes in the body rely on enzymes for detoxification and energy production. Our bodies initially evolved to function on raw enzyme-rich foods that assist the digestive process and use little of our body's natural enzyme supply and energy. ${ }^{26}$ The average diet of mostly cooked food, over time, depletes the body's ability to produce enough enzymes to do all of the important functions they are designed to do, including fully digesting a meal. This results in partially digested fats and proteins being absorbed into the bloodstream, creating Floating Immune Complexes (FIC) ${ }^{27}$ These FICs overwhelm the immune system's ability to dispose of them, so the body stores these harmful toxins in body tissues. ${ }^{28}$ Toxins in the bloodstream cause inflammation, uric acid crystals in joints (gout), allergic reactions, and may result in arterial plaque. ${ }^{29}$ Through time, this continued toxic condition can cause disease. Supplementing our meals with digestive enzymes supports the body's ability to fully digest and utilize food and nutritional supplements. ${ }^{30}$ They also remove digestive remnants and waste products, leaving our pancreas and the other endocrine organs with the resources to produce the metabolic and systemic enzymes needed for such mechanisms as tissue repair and toxin removal. ${ }^{31}$ Friendly flora such as Lactobacillus Acidophilus and bifidobacerium are important to the intestinal tract for maintaining proper $\mathrm{pH}$ and also for controlling the population of potential pathogenic organisms like 
Clostridium and Candida. Plant flora enzymes have now been proven to be very effective in promoting the role of good bacteria to control pathogens. Another role of good bacteria is the actual synthesis of highly favorable natural chemicals in the colon through the fermentation process. ${ }^{32}$ These fermentive products include such molecular species as natural antibiotics and, very importantly, digestive enzymes. These enzymes can play an extremely important role in the digestion of otherwise incompletely digested food substances, especially proteins. ${ }^{33}$

Lactose maldigestion occurs frequently, especially in adults (primary lactose maldigestion) and in individuals with bowel resection or enteritis (secondary lactose maldigestion). It is well established that those with lactose maldigestion experience better digestion and tolerance of the lactose contained in yogurt than of that contained in milk. ${ }^{34}$ The mechanisms involved have been extensively investigated. The importance of the viability of lactic acid bacteria was only speculated because pasteurization reduced the observed digestibility. ${ }^{35}$ At least 2 mechanisms, which do not exclude each other, have been shown: i) digestion of lactose in the gut lumen by the lactase contained in the yogurt bacteria (the yogurt bacteria deliver lactase when lyzed by bile acids); and ii) slower intestinal delivery or transit time of yogurt compared with milk. ${ }^{36}$ In clinical practice, the replacement of milk with yogurt or fermented dairy products allows for better digestion, and decreases diarrhea and other symptoms of intolerance in subjects with lactose intolerance, in children with diarrhea, and in subjects with short-bowel syndrome. ${ }^{37}$ An enhanced digestion of a sucrose load was shown in infants with sucrase deficiency when they consumed Saccharomyces cerevisiae, i.e. a yeast that contains the enzyme sucrase. This is yet another example of a direct effect of a probiotic; however, its relevance in the treatment of sucrase deficient subjects has not been established. ${ }^{38}$

\section{Probiotics}

\section{Effect on immunity}

The gastrointestinal tract functions as a barrier against antigens from microorganisms and food. The generation of immunophysiological regulation in the gut depends on the establishment of indigenous microflora. ${ }^{39}$ This has led to the introduction of novel therapeutic interventions based on the consumption of cultures of beneficial live microorganisms that act as probiotics. ${ }^{40}$ Among the possible mechanisms of probiotic therapy is promotion of a non-immunological gut defense barrier which includes the normalization of increased intestinal permeability and altered gut microecology. ${ }^{41}$ Another possible mechanism of probiotic therapy is improvement of the intestine's immunological barrier, particularly through intestinal IgA responses and alleviation of intestinal inflammatory responses, which produce a gut-stabilizing effect. ${ }^{42}$ Many probiotic effects are mediated through immune regulation, particularly through controlling the balance of proinflammatory and anti-inflammatory cytokines. Data show that probiotics can be used as innovative tools to alleviate intestinal inflammation, normalize gut mucosal dysfunction, and down-regulate reactions of hypersensitivity. ${ }^{43}$

\section{Mechanism}

The exact mechanism by which probiotics function in the GI tract can be defined as: i) competitive exclusion of enteric pathogens; ii) neutralization of dietary carcinogens; iii) production of antimicrobial metabolites; and iv) modulation of mucosal immune responses (Figure 3). ${ }^{44}$

The proper balance between good and bad bacteria largely determines the health of the gut and, as we are learning, the organism as a whole. Probiotics may help prevent an imbalance in which too many bad or harmful bacteria reside in the digestive tract. ${ }^{45} \mathrm{~A}$ growing body of evidence has emerged confirming the positive effect and potential of probiotics in humans. Recent research has implicated probiotics in the treatment of other diseases, including atopic eczema, autism, cancer, and food allergies. ${ }^{46}$ However, to date the vast majority of studies have focused on the defense and integrity of the intestinal flora and the immune system. ${ }^{47}$
Probiotics may take up residence in the body and neutralize the effects of offending bacteria. They colonize the exterior surface of cells in the GI tract and prevent potentially detrimental pathogenic organisms from proliferating. Probiotics also produce components shown to hinder the growth of certain types of harmful bacteria, as well as lower the risk for altered metabolic activity. ${ }^{48}$

The use of probiotics to prevent and treat a wide variety of conditions has gained favor in the past decade. This is in part due to a need to find alternatives to traditional therapies, such as antibiotics, as well as to the lack of efficient treatments for GI ailments. ${ }^{49}$ While there is an increasing number of reports of the efficacy of probiotics in the treatment of diseases such as pouchitis, diarrhea, and IBS, the scientific basis for the use of probiotics is just beginning to be understood. We will focus on the potential applications for probiotics in the treatment of diarrheal disease. Several examples will highlight how probiotics may be selected for and utilized against pathogens causing gastroenteritis. ${ }^{50}$

\section{Gut defense}

The role of the normal intestinal flora as an extremely important host defense mechanism is now beginning to be appreciated. In normal situations, an individual's intestinal flora is highly effective in resisting colonization by potentially pathogenic invaders. ${ }^{51}$ The indigenous flora produce a variety of antimicrobial substances, including colicins and short chain fatty acids, which are potentially bactericidal and bacteriostatic and are, therefore, consid-

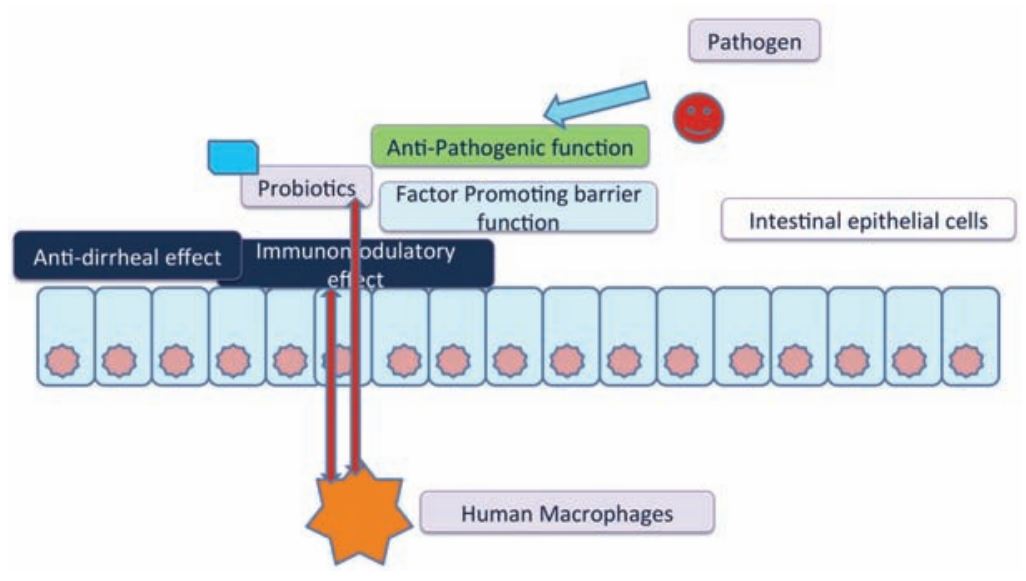

Figure 3. Probiotic and beneficial effect in the intestine. Description of beneficial bacteria. Their serrated factors pathogen and intestinal mucosa. 
ered to inhibit the growth of invading organisms. The intestinal immune system must be able to discriminate between potentially pathogenic microbial antigens and the non-pathogenic dietary and indigenous microbial antigens in order to avoid both invasive infections and chronic inflammatory conditions. ${ }^{52}$ The lack of response to dietary proteins and indigenous microbiota, known as oral tolerance, is the result of several distinct processes. Furthermore, there is growing evidence to suggest that resident microbiota provide the intestinal immune system with endogenous stimuli which are essential for its normal maturation and function. .3

The surface of mucosal membranes is protected by a local adaptive immune system. The gut-associated lymphoid tissue represents the largest mass of lymphoid tissue in the human body. Consequently, it constitutes an important element of the total immunological capacity of the host. ${ }^{54}$ The regulatory events of the intestinal immune response occur in different physiological compartments: aggregated in follicles and Peyer's patches and distributed within the mucosa, the intestinal epithelium, and secretory sites. The intraepithelial T lymphocytes mainly exhibit a suppressor and cytotoxic phenotype, whereas the lamina propria cells exhibit a helper and inducer phenotype. The lamina propria is endowed with lymphocytes belonging to the cell lineage. IgA antibody production is abundant at mucosal surfaces. ${ }^{55}$ In contrast with IgA in serum, secretory IgA is present in dimeric or polymeric form. Secretory IgA is resistant to intraluminal proteolysis and does not activate complement or inflammatory responses, which makes secretory IgA ideal for protecting mucosal surfaces. There are differences between the upper and lower parts of the human gut-associated immune system in the isotype distribution of immunoglobulin-producing cells. IgA1 immunocytes predominate in the small intestine, whereas IgA2-producing cells are most frequent in the colon, the latter being more resistant to bacterial proteases..$^{56}$

\section{Lymphocytes}

The lymphocyte maturation cycle involves antigen transport across Payer's patches and the presentation of antigens to T lymphocytes of a helper and inducer phenotype, which proliferate and induce cell response. ${ }^{57}$ The specific antibody-secreting lymphocytes appear in peripheral blood 2-4 days after antigen exposure, reach a maximum concentration after 6 8 days, and persist in the blood for 2-3 weeks. Studies show that these cells can reside in the gut. Homing receptors on lymphocytes, which interact with ligands on endothelial cells, target the migration of lymphocytes into tissues. ${ }^{58}$ Antigen-specific systemic suppression after oral antigen introduction can be seen after 1-2 days and oral tolerance to systemic challenge becomes established within 5-7 days. Lymphocytes, particularly those of B-cell lineage, can induce enterocytes into M-cell like cells, a unique epithelium that comprises cuboidal epithelial cells, very few goblet cells, and specialized antigen sampling cells, which are typical to Peyer's patches. These cells effectively transfer particles and microbes from the gut lumen into underlying follicles. ${ }^{59}$ The induction of gut-seeking $\mathrm{B}$ cells, i.e. by probiotics, may influence mucosal immunity beyond the secretion of IgA. In addition, intraepithelial and lamina propria sites are activated to produce protective cytokines, and mesenteric lymph nodes secrete polymeric IgA (pIgA) ${ }^{60}$ It has recently been demonstrated that dendritic cells in the lamina propria can extend their appendices between epithelial cells and, via TLR-2 and TLR-4 on their surface, they can sample commensal-bacterial molecular patterns. ${ }^{61}$ The interaction leads to maturation of the dendritic cells and to the release of cytokines, which orchestrate the conversion of precursor T-helper cells (Th0) into the mature, balanced response of the four effector T-helper cell types (Th1, Th2, and Th3/Tr1), an important component in the prevention of disease. ${ }^{62}$ Furthermore, commensal bacteria can cross microfold cells and interact with antigen-presenting cells in mesenteric lymph nodes to activate naive plasma cells into becoming pIgA-producing B cells. pIgA, in turn, coats the mucosal surface to control subsequent microbial and antigen penetration. ${ }^{63}$

There is an intimate interplay between different subsets of T cells and antigen-presenting cells, such as dendritic cells, in the intestine. In murine models, high basal levels of IL4 , IL-10 and GF- $\beta$ expression have been detected in the intestinal mucosa and this cytokine milieu may be crucial for the induction of Th2 and Th3 type responsiveness. ${ }^{64}$ However, as recently pointed out, there may be major differences between species in mucosal immune responses. ${ }^{65}$ In fact, reported data indicate a Th1-skewed cytokine profile as a constant finding in the human intestine. ${ }^{66} \mathrm{~A}$ transient induction of IFN- producing Th1 cells has been detected in the early phases of oral tolerance formation. Even though both Th1 and Th2 cytokines regulate the function of Th3 cells, neither is essential for the induction of peripheral tolerance in a murine model ${ }^{67}$ Therefore, the individual role of each functional subset of $\mathrm{T}$ cells in the inductive phase of oral tolerance remains to be clarified, but it is evident that Th3 cells provide tolerogenic suppression both in the intestine and in other target organs. ${ }^{68-71}$
The small intestine is challenged by a myriad of antigens encountered by way of the enteric route ${ }^{72,73}$. Furthermore, the small intestine is exposed to rapid and constant changes in the composition of the antigen load. ${ }^{74}$ Most antigens are excluded by a wellfunctioning mucosal barrier in the gut. ${ }^{75}$ In addition to the first line of gut defense, immune exclusion and specialized antigen transport mechanisms are to be found in the villous epithelium. ${ }^{76}$ Antigens are absorbed across the epithelial layer by transcytosis; here, the main degradative pathway entails lysosomal processing of the antigen. ${ }^{77}$ This second line of defense, immune elimination, is directed toward the removal of antigens that have penetrated the mucosa. A minor pathway allows for the transport of unprocessed antigens. ${ }^{78}$ Peyer's patches, crucial in determining the subsequent immune responses to the presence of the antigen, are covered by the $\mathrm{M}$ cells. ${ }^{79}$ In general, antigen transport across this epithelium is characterized by rapid uptake and reduced degradation. Antigens are presented to subjacent T cells; these differentiate into various effector cells that mediate active immune suppression and promote the differentation of IgA-secreting B cells. ${ }^{80}$ As a result of the absorption process across the intestinal mucosa, dietary antigens are altered into a tolerogenic form (Figure 3). Consequently, hyporesponsiveness to antigens, e.g. food proteins, and oral tolerance are hallmarks of the intestinal immune system. ${ }^{81}$

\section{Immune response}

There is strong scientific evidence to support the effects of probiotics on the immune system, providing irrefutable proof that certain probiotic strains play a role in modulating both non-specific and specific host immune responses. Non-specific, or innate, immune responses are a host's first line of defense. Natural killer cells and phagocytes, residing in the peripheral blood and tissues, are the major cellular effectors of non-specific immunity. ${ }^{82}$ Natural killer cells effectively fight off viruses, whereas phagocytic cells protect against microbial infections. Both produce a variety of compounds that can destroy both invasive materials as well as normal tissues. The enormous implications of this are discussed below. ${ }^{83}$

Specific immune responses can be separated into two categories: humoral immunity, and cell-mediated immunity. In the humoral immune response, B lymphocytes synthesize specific immunoglobulin molecules, or antibodies, that are excreted from the cell and bind to the invading substance. ${ }^{84}$ In the cellular 
immune response, T lymphocytes, bearing immunoglobulin-like molecules on their surfaces, recognize and kill foreign or aberrant cells. T cells can be divided into 2 subtypes according to their cytokine profile: Th1 and Th2. Th1 cells are essential to cell-mediated immunity and produce IL-2, IFN-g and tumor necrosis factor a (TNF- $\alpha) .85$ The main products of Th2 are IL-4, IL-5, and IL-10 and are associated with humoral immunity and allergic responses (Figure 3).

Dietary consumption of certain probiotic strains have been shown to enhance non-specific immunity, including phagocytosis and lymphocyte proliferation demonstrating the effectiveness of probiotics in stimulating cellular immune responses. ${ }^{3,86}$ Healthy middle-aged and elderly men and women have been shown to experience a significant enhancement of cell phagocytosis and natural killer cell tumor killing activity following twice daily consumption of $B$. lactis. The authors suggest that the enhanced immunity observed in relation to the $B$. lactis may be largely related to the secretion of pro-cellular immunity cytokines, such as interleukin-12 and interleukin-18, which simulate natural killer cell activity and interferon production. ${ }^{87}$ These results support that of another study in which consumption of $B$. lactis was positively associated with increases in the total proportions of T lymphocytes and natural killer cells. ${ }^{88}$

Probiotics play an essential role in the intestinal mucosa barrier, including modulating intestinal immune response and competitively inhibiting the adhesion of pathogenic bacteria to the epithelial wall of the intestine. ${ }^{89}$ Intestinal epithelium plays an important role in innate immunity. When stimulated by cytokines, such as TNF- $\alpha$, the intestinal epithelia release pro-inflammatory cytokines, including IL-8 and IL-10. ${ }^{90}$ However, in some gastrointestinal diseases, such as IBD and acute gastroenteritis, cytokines are activated and produce excessive inflammatory products negatively affecting the immunological capacity of the epithelial cells. ${ }^{91}$ Resident Bifidobacterium and Lactobacillus actively inhibit the pro-inflammatory response by inhibiting the secretion of IL-8, thereby suggesting the use of probiotics in the management of intestinal diseases. This has vast applications for quenching a potentially out-ofcontrol immune system as seen in autoimmune diseases and inflammation disorders. ${ }^{92}$

Many probiotic strains have been studied in relation to their role in the control of inflammatory responses to intestinal antigens. ${ }^{93}$ More specifically, many clinical and experimental studies indicate that microflora imbalance of the gut is associated with intestinal inflammation. For example, one group studied the effect of oral administration of
Lactobacillus rhamnosus on cytokine secretion and T-lymphocyte activation, thus demonstrating the positive immunomodulating effects of oral administration of lactic acid bacteria. ${ }^{8}$ Healthy participants taking a daily oral dose of 2 billion colony forming units (cfu) of $L$. rhamnosus experienced a reduced secretion of proinflammatory TNF- $\alpha$ and increased IL-10 and IL-4 activity. ${ }^{94}$

TNF- $\alpha$ is key to the pathogenesis of altered mucosal immunity. A critical factor in the pathogenesis of Crohn's disease (CD) is the secretion of TNF- $\alpha$ by T lymphocytes.$^{95} \mathrm{Co}$-cultures of inflamed tissue with various probiotic strains have been proven to significantly reduce TNF- $\alpha$ secretion. ${ }^{96}$ Since transcriptional control of IL-8 is mediated by transcription factor NF-kb, it has been hypothesized that the normal intestinal microflora down-regulates inflammation by inhibiting NF-kb activation. This hints at a possible probiotic genomeceutical intervention. ${ }^{97}$

As we have seen, therapeutic administration of probiotics is often advocated for their immunomodulatory properties and anti-inflammatory activities at mucosal barrier sites. ${ }^{98}$ However, only recently have the molecular mechanisms by which probiotics modulate immune responses been clarified (Table 1). Immunostimulating DNA sequences have been shown to effectively reduce or prevent symptoms of colitis in animal studies. ${ }^{99}$ Furthermore, administration of irradiated probiotics significantly improve experimental colitis in murine models, as do viable probiotic strains, suggesting that the anti-inflammatory activities associated with probiotics are mediated by their own DNA, rather than products of their metabolism or intestinal colonization. ${ }^{100}$ This theory is further supported by data suggesting that genomic DNA released by exogenous bifidobacteria provide a stimulus for mucosal IL-10 production in human peripheral blood mononuclear cells. ${ }^{100}$ The interesting conclusion that may be made in the light of this research is that dead bacteria ingested during probiotic administration have a therapeutic effect in addition to the viable cells. ${ }^{101}$

\section{Specific immunity}

L. rhamnosus and $L$. acidophilus were found to effectively stimulate Th1 cells, whereas $B$. lactis showed no effect. ${ }^{102}$ Th1 cells are known to suppress immunoglobulin E (IgE), an indicator of allergy. In a study by Kalliomaki et al., Th1 cells inhibited IL-4 secretion, thereby suppressing IgE production. It can, therefore, be postulated that certain strains of probiotics may inhibit IgE-mediated allergic responses through selective stimulation of Th1 cells. ${ }^{103}$ In fact, probiotics have successfully been used in the prevention and treatment of allergic disorders in humans.

Mucosal inflammation is characteristic of most allergic disorders occurring in the intestinal tract. Food allergies are able to alter gut motility and are often accompanied by diarrhea, malabsorption, and abdominal pain. Many experts believe that the increase in allergic disease may be associated with the improved hygiene in our society. ${ }^{104}$ By minimizing our exposure to antigens, we fail to stimulate the gut immune system. As a result, lymphocytes that would normally differentiate to become Th1 cells differentiate into Th2 cells capable of producing inflammatory cytokines. ${ }^{105}$ However, by challenging the microflora of the gut, it is possible to alter the balance of bacteria and boost the immune system. ${ }^{106}$ That is to say, probiotics appear to be able to exert a genomeceutical effect on T cells and beneficially shift their expression profile from a Th1 to a Th2 phenotype. Intact milk proteins are known to stimulate the secretion of proinflammatory cytokines in susceptible patients, such as those with cow's milk allergy. Specific strains of lactic acid bacteria promote the gut mucosal barrier, protecting the host against allergic sensitization. ${ }^{107}$ In particular, Lactobacillus rhamnosus has been shown to down-regulate hypersensitivity reaction and intestinal inflammation in patients with food allergy through improved antigen-specific immune responses, prevention of permeability defects, and modulating antigen absorption of the mucosal membrane .08

The ability of probiotics to confer enhanced humoral and cell-mediated resistance against pathogens has been well-documented. ${ }^{109}$ For example, it was demonstrated that a significant increase in lymphocyte proliferative responses, phagocytic capacities, and localized antibody production occurs in response to oral administration of lactic acid bacteria in mice infected with Salmonella typhimurium. ${ }^{110}$ Lactobacillus casei has been associated with increases in specific mucosal and serum antibody responses in children with acute rotavirus diarrhea. ${ }^{111}$

The inhibitive effect of probiotics on pathogens is generally dependent on the reduction of pathogen viability or through interference with adhesion and/or invasion of the pathogen. However, in a study in which Lactobacillus strains were tested in an in vitro model of enterohemorrhagic Escherichia coli infection of a human colon epithelial cell line, the protective affect was due to the presence of viable $L$. rhamnosus cells. ${ }^{112}$ In this model, killed L. rhamnosus and other Lactobacillus strains did not have any impact on the inhibitory effect. Because the positive effect of L. rhamnosus was not dose-dependent, it was 
postulated that an intimate interaction between the host cell responses occurred, thereby minimizing the internalizing reaction. ${ }^{113}$

Ingestion of specific probiotics has been shown to have immunomodulatory effects on many aspects of humoral and cell-mediated immunity. In one study, designed to examine the relationship between oral administration of probiotics and immunity in mice, the results indicate strain-dependent variation in the ability of probiotics to influence T-cell activation. ${ }^{114}$

The type of T-cell response, whether it be a Th1, Th2, or Th3/Tr1 response, is controlled predominantly by interactions between DC and
T cells. In humans, induced IL-10 by DC and coculture of naive $\mathrm{T}$ cells with probiotic-treated DC led to a decrease in Thl polarized cells. In a different experimental system in which monocyte-derived DC were cultured with the probiotic $L$. rhamnosus and the subsequent effect on T cells was assessed, decreased T-cell proliferation and T-cell cytokine production, particularly IL-2, IL-4, and IL-10, was demonstrated. ${ }^{115}$ This in vitro effect of $L$. rhamnosus on DC and subsequent T-cell hyporesponsiveness was reflected in in vivo studies in which healthy controls and patients with CD were fed $L$. rhamnosus for two weeks. ${ }^{116}$ Ingestion of $L$. rhamnosus reduced IFN- $\gamma$ and IL-2 production by peripheral $\mathrm{T}$ cells in $\mathrm{CD}$ patients and also reduced IL-4 production in healthy controls. ${ }^{117}$ Probiotic bacteria influence the generation of regulatory $\mathrm{T}$ cells in a murine model of contact dermatitis. Daily oral administration of fermented milk containing the probiotic $L$. case $i$ DN-114 001 reduced antigen-specific skin inflammation by controlling the antigen-specific T-cell response in hapten 2,4-dinitrofluorobenzene, a model of allergic contact dermatitis mediated by CD8+ CTL and controlled by CD4+ regulatory T cells. ${ }^{118}$ The alleviation of contact hypersensitivity by prior feeding with L. casei was due to downregulation of the hapten-specific CD8+ T-cell response as indicated by a decrease in expansion of hapten-specific IFN $\gamma$-producing CD8+ effectors. Furthermore,

Table 1. Examples of probiotics with proven anti-inflammatory properties classified by their mechanisms of action.

\begin{tabular}{|c|c|}
\hline Probiotic & Results \\
\hline B. longum & Improvement of clinical appearance of chronic inflammation in patients, decreases in TNF- $\alpha$ and IL-1 $\alpha$ s. ${ }^{200}$ \\
\hline BIFICO (3 bifidobacteria species) & $\begin{array}{l}\text { Prevention of flare-ups of chronic ulcerative colitis, inactivation of NF- } \kappa \mathrm{B} \text {, decreased expressions of TNF- } \alpha \text { and } \\
\text { IL- } 1 \beta \text { and elevated expression of IL-10. }{ }^{201}\end{array}$ \\
\hline L. salivarius ssp. salivarius CECT5713 & $\begin{array}{l}\text { Recovery of inflamed tissue in TNBS model of rat colitis, increase in TNF- } \alpha \text { and iNOS (inducible NO synthase) } \\
\text { expression. }{ }^{202}\end{array}$ \\
\hline L. fermentum, L.reuteri & Improvement of histology in a TNBS model of rat colitis, decreased levels of TNF- $\alpha$ and i-NOS expression. ${ }^{203}$ \\
\hline L. casei Shirota & $\begin{array}{l}\text { Improvement in murine chronic inflammatory bowel disease, downregulation of proinflammatory cytokines such } \\
\text { as IL-6 and IFN- } \gamma^{204}\end{array}$ \\
\hline L. casei DN-114 001 & $\begin{array}{l}\text { Reduction in numbers of activated T lymphocytes in the lamina propria of Crohn's disease mucosa, decrease of } \\
\text { IL- } 6 \text { and TNF- } \alpha^{205}\end{array}$ \\
\hline L. plantarum $299 \mathrm{v}$ & $\begin{array}{l}\text { Decreased IL-12, IFN- } \gamma \text { and IG2a at the mucosal level of specific pathogen free IL-10 KO mice. Decreased mesen- } \\
\text { teric lymph node IL-12 and IFN- } \gamma \text { production as well as histological colitis scores in the pre-treatment of GF mice } \\
\text { that were exposed to normal flora. }{ }^{206}\end{array}$ \\
\hline L. rhamnosus $\mathrm{GG}$ & $\begin{array}{l}\text { Alleviating intestinal inflammation, decrease in TNF- } \alpha \text {. Specific inhibition of macrophages TNF- } \alpha \text { production by a } \\
\text { contact independent mechanism. }\end{array}$ \\
\hline L. salivarus UCC118 & $\begin{array}{l}\text { Reduced production of proinflammatory cytokines in IL-10 KO mice injected subcutaneously with the probiotic } \\
\text { strain. } 208\end{array}$ \\
\hline L. salivarus UCC118 & $\begin{array}{l}\text { Reduction of } C \text {. perfringes, coliforms and enterococcus levels in IL-10 KO mice. }{ }^{209} \\
\text { Production of a peptide that inhibits a broad range of pathogens such as Bacillus, Staphylococcus, Enterococcus, } \\
\text { Listeria and Salmonella species. }{ }^{210}\end{array}$ \\
\hline L. reuteri & $\begin{array}{l}\text { Decreased concentration of colonic Lactobacillus species and increased concentration of mucosal adherent } \\
\text { bacteria associated with colitis attenuation. }{ }^{211} \\
\text { Delayed relapse into pouchitis after surgical resection in human patients. }{ }^{212} \\
\text { L. rhamnosus } G G \text {, L. rhamnosus Lc705, P. freudenreichii ssp. shermanii JS and B. breve Bb99. }{ }^{213} \\
\text { Alleviating IBS symptoms. }{ }^{217}\end{array}$ \\
\hline B. and L. plantarum & Improvement of the disease activity index in an induced rat colitis model. ${ }^{214}$ \\
\hline L. rhamnosus GG & Improvement in the clinical status in children with mildly to moderately active stable Crohn's disease. ${ }^{215}$ \\
\hline L. casei Shirota & Improvement in the clinical condition of murin DSS model of ulcerative colitis. ${ }^{216}$ \\
\hline L. plantarum NCIMB8826 $\Delta$ Dlt & $\begin{array}{l}\text { Reduction in secretion of proinflammatory cytokines by peripheral blood mononuclear cells and monocytes and } \\
\text { increase in IL-10 production in a murine colitis model. }\end{array}$ \\
\hline Lc. lactis IL-10 & Reduction in colitis in mice treated with DSS and prevention of the onset of colitis in IL-10 knockout mice. \\
\hline L. casei BL23 MnKat & $\begin{array}{l}\text { Reduction in cecal and colonic inflammatory scores in a DSS-induced colitis model. } \\
\text { Significant reduction of physiological damage in a TNBS-induced colitis model. }{ }^{218} \\
\text { Slight increase in catalase activity in the intestines and prevention of colon cancer in mice administered the } \\
\text { cancer-inducing drug DMH. }\end{array}$ \\
\hline $\begin{array}{l}\text { Lc. lactis NZ9811 and } \\
\text { L. plantarum NCIMB8826+pNZ804 sodA }\end{array}$ & Reduction in macroscopic damage in rats administered TNBS to induce colitis. ${ }^{19,30,210}$ \\
\hline L. gasseri NC1501 (sod overexpression) & Reduction in inflammation in IL-10 deficient mice. ${ }^{210}$ \\
\hline L. casei $\mathrm{BL} 23+$ sodA & $\begin{array}{l}\text { Attenuation of colonic histological damage scores in a DSS-induced colitis model. } \\
\text { Significant reduction in physiological damage in a TNBS-induced colitis model. }{ }^{125}\end{array}$ \\
\hline
\end{tabular}


experiments in mice deficient in CD4+ cells indicated that these cells are mandatory for the effect of $L$. casei on contact hypersensitivity. ${ }^{119}$ It was proposed that $L$. case $i$ reduced contact hypersensitivity by direct or indirect activation of regulatory CD4+ T cells. ${ }^{120}$ IL-10-dependent regulatory $\mathrm{CD} 4+\mathrm{T}$ cells bear surface TGF- $\beta$. These cells appear to be similar to CD25+ regulatory $\mathrm{T}$ cells that inhibit cell-transfer colitis by a TGF $\beta$-dependent mechanism. ${ }^{21}$

\section{Clinical applications}

\section{The effect of probiotics on bacteria}

Probiotics reduce plasma levels of bacterial endotoxin concentrations, at least in part, by inhibiting translocation of bacteria across the GI lumen into the bloodstream. Lactobacillus colonization in germ-free rats has been shown to decrease gut permeability to mannitol. ${ }^{122}$ In addition, administration of Lactobacillus to IL10 knockout mice decreased translocation of bacteria to extraintestinal sites and reduced myeloperoxidase concentrations, often associated with inflammation in the bowel. ${ }^{123}$ Decreases in translocation of bacteria may occur as a result of the ability of probiotics to tighten the mucosal barrier. Although very little is known about specific molecular mechanisms by which indigenous flora tighten the mueosal barrier, this may be accomplished by bacterial-epithelial crosstalk and upregulation of growth factors and receptor sites. ${ }^{124}$ Whatever the method of barrier to bacterial entry, the net effect is to modulate systemic intestinal allergy and inflammation. Allergyinduced intestinal inflammation mediated by fecal tumor necrosis factor-alpha is decreased by Lactobacillus. ${ }^{125}$ Lactobacillus also increases mucosal regeneration and reduces fecal urease production, a correlate of inflammation associated with chronic arthritis. ${ }^{126}$ There are several ways probiotic microflora can prevent pathogenic bacteria from adhering and colonizing gut mucosa (Table 2). Probiotics disallow colonization by disease-provoking bacteria through competition for nutrients, immune system upregulation, production of antitoxins, and upregulation of intestinal mucin genes. Increased mucous production prevents adherence and colonization by competing microflora, thereby preventing any imbalance. ${ }^{127}$

The inhibition of pathogenic bacteria by probiotics is an orchestrated combination of structure and function. Interestingly, bacteriocins (antibacterial compounds produced by $L$. acidophilus) are antagonistic within a specific spectrum by inhibiting other strains of Lactobacilli. Therefore, the practice of combining probiotics needs to include beneficial bacteria that do not inhibit other included

\section{strains. ${ }^{128}$}

Adherence of normal, beneficial flora competitively inhibits colonization of the mucosa by pathogenic bacteria and reduces overstimulation of the immune system. A healthy colon with adequate mucus production and appropriate bacterial colonization prevents the adherence of pathogenic bacteria, modulates disease processes, and prevents widespread inflammatory disorders. ${ }^{129}$

Probiotics used to treat intestinal ailments or whose mode of action is thought to be exerted in the intestinal tract must be able to survive both acid and bile stress during transit through the gut. The physiological state of the microbe is an important characteristic that determines whether cells will be susceptible to different types of environmental stress. ${ }^{130}$ For example, exponentially growing cells of $L$. reuteri are much more susceptible to killing by bile salts than cells in stationary phase. Thus, it is important to consider the physiological state of the cells in terms of stress adaptation not only for survival in the host but also during production. Second, the expression of bioactive molecules, which are most often responsible for the health benefits exerted by probiotics, is often growth-phase dependent. ${ }^{131}$ For example, our groups have been investigating the production of immunomodulatory compounds and antimicrobial agents by strains of L. reuteri. In both cases, these compounds are more highly expressed in the entry into and during stationary phase. ${ }^{132}$

Commensal-derived probiotic bacteria have been implicated as therapy for a range of digestive diseases, including antibiotic-associated colitis, Helicobacter pylori gastritis, and traveller's diarrhea. ${ }^{133}$ Probiotic formulations may include single strains or combinations of strains. $L$. reuteri is indigenous to the human gastrointestinal tract, is widely present in mammals, and has never been shown to cause disease. In human trials, probiotic treatment with $L$. reuteri in small children with rotaviral gastroenteritis reduced the duration of disease and facilitated patient recovery, while in another study, it prevented diarrhea in infants. ${ }^{134}$ Despite the promising data from clinical trials, the primary molecular mechanisms underlying the antipathogenic properties of $L$. reuteri remain unknown. ${ }^{135}$ Probiotics may be effective in preventing or treating infectious gastroenteritis. The relative impact on disease incidence varies depending on the specific probiotic strain and patient population, and consistent benefits for disease prevention have been demonstrated in multiple clinical studies. In one disease prevention study, supplementation with Bifidobacterium lactis significantly reduced the incidence of acute diarrhea and rotavirus shedding in infants. ${ }^{136}$ Studies that examined potential benefits of probiotics for preventing antimicrobial-associated diarrhea have yielded mixed results. One prevention study reported a reduction in incidence of antimicrobial-associated diarrhea in infants by $48 \%$. Probiotics may also be incorporated in treatment regimens for infectious gastroenteritis. ${ }^{137}$ Several metaanalyses of numerous clinical trials with different probiotics documented reductions in the length of the disease course of gastroenteritis that ranged from 17 to $30 \mathrm{~h}$. Examined in another way, meta-analyses of probiotics used in clinical trials of gastroenteritis noted significantly reduced incidence of diarrhea lasting longer than three days (i.e. prolonged diarrhea). ${ }^{138}$ The incidence of prolonged diarrhea was diminished by $30 \%$ or $60 \%$, respectively, depending on the study. The probiotic agent, LGG, contributed to a significant reduction in rotavirus diarrhea after three days of treatment administered to children as part of oral rehydration therapy. In addition, probiotics are promising agents for preventing and treating antimicrobial-associated diarrhea, although intention-to-treat analyses have not demonstrated any benefit. ${ }^{139}$

\section{Antibiotic-associated diarrhea}

One of the most well-recognized uses of probiotics is for diarrheal diseases. The prevention and management of acute viral and bacterial diarrhea, as well as the control of antibiotic-associated diarrhea, are areas of significant potential benefit. ${ }^{140} \mathrm{~A}$ number of specific strains, including Lactobacillus GG, L. reuteri, Saccharomyces boulardii, Bifidobacteria species, and others, have been shown to have significant benefit for diarrhea. In the pediatric population, probiotics appear to benefit viral diarrhea, possibly by increasing secretory IgA and decreasing viral shedding, suggesting an immunological mechanism. ${ }^{141}$ Although numerous different probiotic strains, doses, and populations in these studies make it difficult to generalize, it is clear probiotic agents are becoming an important tool in the treatment of gastrointestinal problems in infants and children. ${ }^{142}$

Although gastroenteritis as the cause of acute diarrhea may resolve spontaneously within a few days, it can be associated with morbidity, and increased direct and indirect medical costs. Acute diarrheal episodes can be related to viral, bacterial, or parasitic pathogens. ${ }^{143}$ Several studies have demonstrated improvement when acute diarrheal disorders, including rotavirus infection, traveller's diarrhea, and more serious bacterial infections such as Clostridium difficile, are treated with probiotics. Importantly, studies using Lactobacillus species or Saccharomyces boulardii suggest a beneficial role during $C$. difficile-related infections. In populations with 
small bowel bacterial overgrowth, and in particular those with short bowel syndrome, Lactobacillus species were shown to be efficacious in ameliorating the symptom complex. ${ }^{144}$ However, in 10 patients during a 7-day, doubleblind, randomized trial comparing antibiotic therapy to Saccharomyces boulardii, $S$. boulardii was ineffective in eliminating overgrowth of small bowel intestinal bacteria once it was established. ${ }^{145}$

In vitro studies demonstrate probiotic agents inhibit adherence of dysbiotic organisms to intestinal epithelial cells. This inhibition is hypothesized to be mediated through the ability to increase expression of MUC2 and MUC3 intestinal mucins. ${ }^{146}$ Bacterial-toepithelial cell binding is a multi-stage process, the first stage of which is characterized by an initial interaction of bacteria with the enterocyte layer. Probiotics increase intestinal mucin production, which prevents the attachment of enteropathogens. ${ }^{147}$ The attachment could be prevented by steric hindrance (a slight structural difference in the bacterial ligand interfering with proper attachment to the receptor) or through competitive inhibition for attachment sites on mucins mimicking epithelial cell bacterial attachment sites. Enhancement of innate defense mechanisms in the gastrointestinal tract, such as mucin production, might be preventive or therapeutic, but this still remains to be clarified. ${ }^{148}$

\section{Probiotics in irritable bowel syndrome}

Probiotics exhibit a direct effect in the gut in the treatment of inflammatory and functional bowel disorders. In one of the most common functional bowel disorders, IBS, Lactobacillus strains were shown in clinical trials to reduce abdominal pain, bloating, flatulence and constipation. ${ }^{149}$ It was also observed that Saccharomyces boulardii decreased diarrhea in IBS, but was not effective in alleviating other symptoms of the syndrome.

IBS is a widespread and multifactorial functional disorder of the digestive tract. It affects $8-22 \%$ of the population with a higher prevalence in women. It accounts for $20-50 \%$ of referrals to gastroenterology clinics and is characterized by abdominal pain, excessive flatus, variable bowel habit and abdominal bloating for which there is no evidence of detectable organic disease. ${ }^{150}$ Suggested etiologies include gut motility and psychological disorders as well as psycho-physiological phe- nomena and colonic fermentation. A large proportion of patients have periods of time characterized by sudden and unforeseeable changes in the two main symptoms, constipation and diarrhea, even within a few days. ${ }^{151}$ It is very likely that the syndrome represents different groups of patients probably with a different pathogenesis. IBS may follow gastroenteritis and may be associated with an abnormal gut flora and with food intolerance. The fecal microflora in some of these patients has been shown to be abnormal with higher numbers of facultative organisms and low numbers of lactobacilli and bifid bacteria. ${ }^{152}$

Bacteria are the major component of formed stools and are influenced by substrates arriving with the ileal affluent. Stool production is related to quantitative and qualitative aspects of the colonic microflora and nearly $80 \%$ of the fecal dry weight consists of bacteria, $50 \%$ of which are viable. ${ }^{153}$

Although there is no evidence of food allergy in IBS, food intolerance has been identified and exclusion diets are beneficial to many of these patients. Food intolerance may be caused by an abnormal fermentation of food residues in the colon as a result of disruption of the normal flora. ${ }^{154}$

Table 2. Clinical application of probiotics.

\begin{tabular}{|c|c|c|}
\hline Disease & Probiotic & Results \\
\hline $\mathrm{CD}$ & S. boulardii & $\begin{array}{l}\text { Relapse in } 6 \% \text { of patients supplemented with probiotic strain versus } 38 \% \text { with conventional treatment only. Median } \\
\text { pediatric CD activity index scores at four weeks were } 73 \% \text { lower than baseline and intestinal. }{ }^{181}\end{array}$ \\
\hline $\mathrm{CD}$ & Lactobacillus & $\begin{array}{l}\text { GG The number of specific antibody secreting cells in the IgA class to } \beta \text {-lactoglobulin increased significantly from } \\
0.2(0.04-1.3) \text { to } 1.4(0.3-6.0) / 10^{6} \text { cells and to casein from } 0.3(0.1-1.4) \text { to } 1.0(0.2-4.8) / 10^{6} \text { cells. } .^{182,183}\end{array}$ \\
\hline IBS & B. infantis 35624 & Alleviation of IBS symptoms and normalization of the antiinflammatory-proinflammatory ratio. ${ }^{184}$ \\
\hline IBS & $\begin{array}{l}\text { BIFICO } \\
\text { (3 bifidobacteria species) }\end{array}$ & $\begin{array}{l}\text { Relapse in } 20 \% \text { of patients in probiotic group versus } 93 \% \text { in the placebo group. The probiotic impeded the } \\
\text { activation of NF- } \kappa \text { B, decreased the expressions of TNF- } \alpha \text { and IL- } 1 \beta \text { and increased the expression of IL-10185,186 }\end{array}$ \\
\hline IBS & $\begin{array}{l}\text { L.rhamnosus } \mathrm{GG} \text {, } \\
\text { L. rhamnosus } \mathrm{Lc705,} \\
\text { P. freudenreichii spp } \\
\text { shermanii JS, B. breve } \\
\text { Bb99 }\end{array}$ & $\begin{array}{l}\text { The total symptom score (abdominal pain+distension+flatulence+borborygmi) was reduced } 42 \% \text { in the } \\
\text { probiotic group compared with } 6 \% \text { in the placebo group. }{ }^{187,188}\end{array}$ \\
\hline IBS & $\begin{array}{l}\text { Prescript-Assist } \\
\text { (probiotic+prebiotic } \\
\text { complex containing } 29 \\
\text { soil-based, pH-resistant } \\
\text { microflora) }\end{array}$ & The probiotic + prebiotic treatment showed short-term and long-term reductions in IBS symptoms. ${ }^{189}$ \\
\hline IBS & Prescript-Assist & $\begin{array}{l}\text { The probiotic+prebiotic treatment was associated with significant reductions in } 3 \text { sub-syndromic factors of IBS: } \\
\text { 1) general ill feelings; 2) nausea and indigestion; 3) flatulence and colitis. }{ }^{190}\end{array}$ \\
\hline $\mathrm{PCH}$ & $\begin{array}{l}\text { VSL\#3 (probiotic } \\
\text { preparation containing } \\
3 \text { B., } 4 \text { L. and } 1 \text { St. strains) }\end{array}$ & $\begin{array}{l}\text { The probiotic mixture was effective in maintaining antibiotic-induced remission for at least one year in patients } \\
\text { with recurrent or refractory pouchitis (85\%) versus } 6 \% \text { in the placebo group. }{ }^{191-193}\end{array}$ \\
\hline $\mathrm{PCH}$ & VSL\#3 & $\begin{array}{l}10 \% \text { of patients treated with probiotics had an episode of acute pouchitis compared with } 40 \% \text { treated with } \\
\text { placebo. Treatment with probiotic improved IBS Questionnaire score versus placebo. }{ }^{194-197}\end{array}$ \\
\hline $\mathrm{UC}$ & E. coli Nissle 1917 & $\begin{array}{l}\text { The probiotic treatment was just as effective as the conventional treatment (mesalazine) in maintaining } \\
\text { remission. }{ }^{198}\end{array}$ \\
\hline UC & VSL\#3 & Probiotic supplementation improved remission compared to conventional treatment (balsalazide) alone. ${ }^{199}$ \\
\hline UC & VSL\#3 & $\begin{array}{l}\text { Probiotic preparation maintains remission }(75 \%) \text { and there was no relapse (0\%) of intestinal disease while on } \\
\text { probiotics. }{ }^{199}\end{array}$ \\
\hline
\end{tabular}


To assess whether preceding gastroenteritis or food intolerance were associated with colonic malfermentation, Bamford et al. conducted a crossover controlled trial with a standard diet and an exclusion diet matched for macronutrients in 6 female patients with IBS and 6 female controls. ${ }^{155}$ In this study, fecal excretion of fat, nitrogen, starch, and nonstarch polysaccharide was measured during the last $72 \mathrm{~h}$ of each diet. The total excretion of hydrogen and methane were collected over 24 $\mathrm{h}$ in a purpose-built $1.4 \mathrm{~m}^{3}$ whole body calorimeter. Breath hydrogen and methane excretion were measured for $3 \mathrm{~h}$ after $20 \mathrm{~g}$ oral lactulose. ${ }^{156}$ The maximum rate of gas excretion was significantly greater in patients than in controls. The total gas production in patients was not higher than in controls, whereas hydrogen production. ${ }^{157}$

After lactulose, breath hydrogen was higher on the standard than on the exclusion diet. This means that colonic-gas production, particularly of hydrogen, is greater in patients with IBS than in controls, and both symptoms and gas production are reduced by an exclusion diet. This reduction may be associated with alterations in the activity of hydrogenconsuming bacteria. ${ }^{158}$ It was, therefore, concluded that fermentation may be an important factor in the pathogenesis of this syndrome.

Studies were carried out on the intestinal permeability (Lactulose/mannitol ratio) and histological and immunological features in rectal biopsy specimens from 21 patients with acute Campylobacter enteritis, 10 patients with post-dysenteric IBS, and 12 asymptomatic controls. ${ }^{159}$ They found that the increased enteroendocrine cell counts, $\mathrm{T}$ lymphocytes, and gut permeability, which may survive for more than a year after Campylobacter enteritis, contribute to post-dysenteric IBS, thus offering a rationale to use probiotics for several months after the infectious episode. ${ }^{160}$

\section{Improved lactose digestion and other direct enzymatics effects}

Lactose maldigestion occurs frequently, especially in adults (primary lactose maldigestion) and in individuals with bowel resection or enteritis (secondary lactose maldigestion). It is well-established that persons with lactose maldigestion experience better digestion and tolerance of the lactose contained in yogurt than of that contained in milk. ${ }^{161}$ The mechanisms involved have been extensively investigated. There has been speculation conerning the importance of the viability of lactic acid bacteria since pasteurization reduced the observed digestibility. ${ }^{162}$ At least 2 mechanisms, which do not exclude each other, have been shown: i) digestion of lactose in the gut lumen by the lactase contained in the yogurt bacteria (the yogurt bacteria deliver lactase when lyzed by bile acids); and ii) slower intestinal delivery or transit time of yogurt compared with milk. ${ }^{163}$ In clinical practice, the replacement of milk with yogurt or fermented dairy products allows for better digestion, and decreases diarrhea and other symptoms of intolerance in subjects with lactose intolerance, in children with diarrhea, and in subjects with short-bowel syndrome. ${ }^{164}$ An enhanced digestion of a sucrose load was shown in infants with sucrase deficiency when they consumed Saccharomyces cerevisiae, i.e. a yeast that contains the enzyme sucrase. ${ }^{165}$ This is yet another example of a direct effect of a probiotic; however, its relevance in the treatment of sucrase deficient subjects has not been established. ${ }^{166}$

\section{Ulcerative colitis}

Patients with mild to moderate active colitis, who had been unresponsive or intolerant to standard therapy, received 20-30 $\mathrm{g}$ of a prebiotic germinated barley drink in a non-randomized, open-label fashion. At four weeks, this treatment resulted in significant clinical and endoscopic improvement. ${ }^{167}$ Previous studies with this prebiotic demonstrated positive effects on epithelial cell restitution, suppression of nuclear factor-B binding activity, increased short chain fatty acid production, and enhanced growth of probiotic bacterial strains. Fujimori $e t$ al. conducted a randomized trial of the use of Bifidobacterium-fermented milk in the treatment of ulcerative colitis. ${ }^{168}$ Eleven subjects received the Bifidobacterium-fermented milk for one year, whereas the control group did not. Exacerbation of symptoms was seen in 3 of the 11 subjects in the group treated with Bifidobacterium-fermented milk and in 9 of 10 in the control group $(\mathrm{P}=0.01)$. Analysis of the microflora and the organic acids of the feces demonstrated a significant reduction in the relative proportion of $B$. vulgatus and in Bacteroidaceae. In an open-label pilot trial with $S$. boulardii, a group of 25 patients with mild to moderate ulcerative colitis received $S$. boulardii for four weeks in addition to mesalamine. ${ }^{169}$ Of the 24 patients who completed the study, 17 achieved clinical remissions. ${ }^{170}$

Finally, human fecal rectal infusions in 6 selected patients with ulcerative colitis were carried out in a novel protocol. ${ }^{171}$ Fecal flora donors were healthy adults. Fecal suspensions were administered as a retention enema daily for five days. Full clinical remission and cessation of ulcerative colitis medication were achieved in all patients. ${ }^{172}$ Interestingly, at 1-13 years after human fecal infusion, all patients were free of endoscopic and histological evidence of ulcerative colitis. ${ }^{173,174}$

\section{Crohn's disease}

In keeping with the concept of an altered probiotic profile in patients with $\mathrm{CD}$, studies using molecular methodology to examine RNA demonstrated that enterobacteria were significantly increased in active quiescent $\mathrm{CD}$ and significantly lower in healthy controls. Interestingly, $30 \%$ of the dominant flora belonged to as yet unidentified phylogenetic groups. ${ }^{175-178}$

Different probiotic strains may have differential effects in patients with CD. Ileal specimens from patients with CD were cultured with various probiotic agents. Release of TNF- $\alpha$ by inflamed mucosa was significantly reduced by co-culture with $L$. casei or Lactobacillus bulgaricus but not with Lactobacillus crispatus or E. coli. ${ }^{179,180}$

Clinical trials with probiotics have shown inconsistent results in treating adult CD (Table 1). ${ }^{181-199}$ A small pediatric non-randomized pilot study suggested that Lactobacillus GG may improve gut barrier function and clinical status in children with mildly to moderately active stable CD. However, in a larger controlled double-blind pediatric study, Lactobacillus GG did not prolong time to relapse in children with $\mathrm{CD} .{ }^{183}$

\section{Pouchitis}

Pouchitis is a non-specific inflammation of the ileal reservoir that may appear after surgery for ulcerative colitis, and results in various clinical symptoms. It is a well-recognized long-term complication of restorative proctocolectomy. 195

The risk of pouchitis increases in patients with a history of extra-intestinal manifestations, primary sclerosing cholangitis, positive serology for perinuclear anti-neutrophil cytoplasmic antibodies, and backwash ileitis. ${ }^{196}$

Pouchitis is associated with bacterial overgrowth and dysbiosis, and antibiotics represent the treatment of choice. The distal ileum and the large bowel, the sites with the highest bacterial concentration, are the most frequently affected by inflammation. Enteric bacteria or their products have been detected within the inflamed mucosa. ${ }^{197}$

A significant decrease in lactobacilli and bifidobacteria concentrations has been found in ulcerative colitis, CD and pouchitis. Lactobacilli as maintenance showed less frequent relapses of pouchitis than those using placebo. Diversion of the fecal stream in the small and large intestine reduces the inflammatory action. ${ }^{125}$ The luminal contents and purified bacterial products added to isolated intestinal loops trigger systemic and local signs of inflammation. 
In a study by Campieri et al., ${ }^{179} 7$ patients, after clinical, endoscopic, and histological diagnoses of inflammation of the ileal pouch anal anastomosis with a pouchitis disease activity index of more than 7 , were treated with $2 \mathrm{~g} /$ day of rifaximin (a non-absorbable antibiotic) and $1 \mathrm{~g} /$ day of ciprofloxacin for one month. ${ }^{198}$

All patients went into remission during this month, as judged by clinical, endoscopic and histological examination. After remission, all 7 patients were treated with the highly concentrated probiotic mixture VSL3 for nine months. No patient relapsed in this period. All patients who received placebo relapsed. ${ }^{199}$

Intestinal microbiota play an important role in maintaining normal GI function and ensuring that changes in the composition of the intestinal microbiota can contribute to the development of GI function (Table 2). ${ }^{200-219}$ Probiotics maximize the benefits of a healthy diet by supporting normal absorption and assimilation of nutrients in the gut. Maintaining a favorable bacterial balance in the intestines is crucial to achieving and maintaining optimum health.

\section{References}

1. Teitelbuam JE, Walker WA. Nutritional impact of pre- and probiotics as protective gastrointestinal organisms. Annu Rev Nutr 2002;22:107-38.

2. Horvath K, Perman JA. Autism and gastrointestinal symptoms. Curr Gastroenterol Rep 2002;4:251-8.

3. Reber KM, Nankervis CA, Nowicki PT. Newborn intestinal circulation. Physiology and pathophysiology. Clin Perinatol 2002; 29:23-39.

4. Szajewska H, Mrukowicz JZ. Probiotics in the treatment and prevention of acute infectious diarrhea in infants and children: a systematic review of published randomized, double-blind, placebo-controlled trials. J Pediatr Gastroenterol Nutr 2001; 33suppl2:S17-S25.

5. Weizman Z, Asli G, Alsheikh A. Effect of a probiotic infant formula on infections in child care centers: comparison of two probiotic agents. Pediatrics 2005;115:5-9.

6. King CK, Glass R, Bresee JS, Duggan C. Managing acute gastroenteritis among children: oral rehydration, maintenance, and nutritional therapy. MMWR Recomm Rep 2003;52:1-16.

7. Cherayil BJ, Walker WA. Ontogeny of the host response to enteric microbial infection. In: Hecht G. Microbial pathogenesis and the intestinal epithelial cell. Washington DC: ASM Press; 2003. pp.33349 .
8. Head KA, Jurenka JS. Inflammatory bowel disease art I: ulcerative colitis-pathophysiology and conventional and alternative treatment options. Altern Med Rev 2003;8:247-83.

9. Baumgart DC, Sandborn WJ. Inflammatory bowel disease: clinical aspects and established and evolving therapies. Lancet 2007;369:1641-57.

10. Elson C0, Weaver CT. Experimental mousemodels of inflammatory bowel disease: new insights into pathogenic mechanisms. In: Targan SR, Shanahan F, Karp LC. Inflammatory bowel disease. From bench to bedside. New York: Springer Science+Business Media; 2003. pp.1-4

11. National Collaborating Centre for Women's and Children's Health. Diarrhoea and vomiting caused by gastroenteritis: diagnosis, assessment and management in children younger than 5 years. London: RCOG Press at the Royal College of Obstetricians and Gynaecologists; 2009. pp 48-75.

12. DeCamp LR, Byerley JS, Doshi N, Steiner MJ. Use of antiemetic agents in acute gastroenteritis: a systematic review and metaanalysis. Arch Pediatr Adolesc Med 2008;162:858-65.

13. Fonseca BK, Holdgate A, Craig JC. Enteral vs intravenous rehydration therapy for children with gastroenteritis: a metaanalysis of randomized controlled trials. Arch Pediatr Adolesc Med 2004;158:483-90.

14. Foster J, Cole M. Oral immunoglobulin for preventing necrotizing enterocolitis in preterm and low birth-weight neonates [review]. Cochrane Database Syst Rev 2004;CD001816.

15. King CK, Glass R, Bresee JS, et al. Implementing an evidence-based acute gastroenteritis guideline at a children's hospital. Jt Comm J Qual Improv 2002;28: 20-30.

16. Salminen MK, Tynkkynen S, Rautelin H, et al. Lactobacillus bacteremia during a rapid increase in probiotic use of Lactobacillus rhamnosus GG in Finland. Clin Infect Dis 2002;35:1155-60.

17. Schneider CK, Melmed RD, Barstow LE, et al. Oral human immunoglobulin for children with autism and gastrointestinal dysfunction: a prospective, open-label study. J Autism Dev Disord 2006;36:1053-64.

18. Horvath K, Perman JA. Autism and gastrointestinal symptoms. Curr Gastroenterol Rep 2002;4:251-8.

19. Wang B, Li J, Li Q, et al. Isolation of adhesive strains and evaluation of the colonization and immune response by Lacto-bacillus plantarum L2 in the rat gastrointestinal tract. Int J Food Microbiol 2009;132:59-66.

20. West CE, Hammarström ML, Hernell 0. Probiotics during weaning reduce the inci- dence of eczema. Pediatr Allergy Immunol 2009;20:430-7.

21. Zeng J, Li Y-Q, Zuo X-L, et al. Clinical trial: effect of active lactic acid bacteria on mucosal barrier function in patients with diarrhoea-predominant irritable bowel syndrome. Aliment Pharmacol Ther 2008;28:994-1002.

22. Ataie-Jafari A, Larijani B, Alavi Majd H, Tahbaz F. Cholesterol-lowering effect of probiotic yogurt in comparison with ordinary yogurt in mildly to moderately hypercholesterolemic subjects. Ann Nutr Metab 2009;54:22-7.

23. Bu HF, Wang X, Zhu YQ, et al. Lysozymemodified probiotic components protect rats against polymicrobial sepsis: role of macrophages and cathelicidin-related innate immunity. J Immunol 2006;177: 8767-76.

24. Aldridge PD, Gray MA, Hirst BH, Khan CM. Who's talking to whom? Epithelial-bacterial pathogen interactions. Mol Microbiol 2005;55:655-63.

25. Zhou C, Ma F-Z, Deng X-J, et al. Lactobacilli inhibit interleukin-8 production induced by Helicobacter pylori lipopolysaccharide-activated Toll-like receptor 4. World J Gastroenterol 2008;14: 5090-5.

26. Nanthakumar NN, Young C, Ko JS, et al. Glucocorticoid responsiveness in the developing human intestine: possible role in the prevention of necrotizing enterocolitis. Am J Physiol Gastrointest Liver Physiol 2005;288:G85-92.

27. Nanthakumar N, Fusunyan RD, Sanderson IR, Walker WA. Inflammation in the developing human intestine: a possible pathophysiologic basis for necrotizing enterocolitis. Proc Natl Acad Sci U S A 2000;97: 6043-8.

28. Teitelbuam JE, Walker WA. Nutritional impact of pre- and probiotics as protective gastrointestinal organisms. Annu Rev Nutr 2002;22:107-38.

29. Akira S, Takeda K, Kaisho T. Toll-like receptors: critical proteins linking innate and acquired immunity. Nat Immunol 2001;2:675-80.

30. Kalliomaki MA, Isolauri E. Probiotics and down-regulation of the allergic response. Immunol Allergy Clin North Am 2004; 24:739-52.

31. Isolauri E, Sutas Y, Kankaanpaa P, et al. Probiotics: effects on immunity. Am J Clin Nutr 2001;73:444S-450S.

32. Guandalini S, Pensabene L, Zikri MA, et al. Lactobacillus GG administered in oral rehydration solution to children with acute diarrhea: a multicenter European trial. J Pediatr Gastroenterol Nutr 2000;30:54-60.

33. Rosenfeldt V, Michaelsen KF, Jakobsen M, et al. Effect of probiotic Lactobacillus strains in young children hospitalized with 
acute diarrhea. Pediatr Infect Dis J 2002;21:411-6.

34. Costa-Ribeiro H, Ribeiro TC, Mattos AP, et al. Limitations of probiotic therapy in acute, severe dehydrating diarrhea. J Pediatr Gastroenterol. Nutr 2003;36:112-5.

35. Rosenfeldt V, Michaelsen KF, Jakobsen M, et al. Effect of probiotic Lactobacillus strains on acute diarrhea in a cohort of nonhospitalized children attending daycare centers. Pediatr Infect Dis J 2002;21: 417-9.

36. Young RJ, Huffman S. Probiotic use in children. J Pediatr Health Care 2003;17: 277-83.

37. Guarino A, Albano F, Ashkenazi S, et al. European Society for Paediatric Gastroenterology, Hepatology, and NutritionEuropean Society for Paediatric Infectious Diseases evidence-based guidelines for the management of acute gastroenteritis in children in Europe. J Pediatr Gastroenterol Nutr 2008;46Suppl2: S81-122.

38. Canadian Pediatric Society. Oral rehydration therapy and early refeeding in the management of childhood gastroenteritis. Paediatr Child Health 2006;11:527-31.

39. Sanderson IR,Walker WA. Uptake and transport of macromolecules by the intestine: possible role in clinical disorders (an update). Gastroenterology 1993;104:62239.

40. Perin NM, Clandinin MT, Thomson ABR. Importance of milk and diet on the ontogeny and adaptation of the intestine. $\mathrm{J}$ Pediatr Gastroenterol Nutr 1997;24:419-25.

41. Grand RJ, Watkins JB, Torti FM. Development of the human gastrointestinal tract. Gastroenterology 1976;70:790810.

42. Bolte G, Knauss M, Metzdorf I, Stern M. Postnatal maturation of rat small intestinal brush border membranes correlates with increase in food protein binding capacity. Dig Dis Sci 1998;43:148-55.

43. Van der Heijden PJ, Bianchi AT, Dol M, et al. Manipulation of intestinal immune responses against ovalbumin by cholera toxin and its B subunit in mice. Immunology 1991;72:89-93.

44. Bamford CV, d'Mello A, Nobbs AH, et al. Streptococcus gordonii modulates Candida albicans biofilm formation through intergeneric communication. Infect Immun 2009;77:3696-704.

45. Banbula A, Bugno M, Kuster A, et al. Rapid and efficient inactivation of IL-6 gingipains, lysine- and arginine-specific proteinases from Porphyromonas gingivalis. Biochem Biophys Res Commun 1999;261: 598-602.

46. Banerjee P, Merkel GJ, Bhunia AK. Lactobacillus delbrueckii ssp. bulgaricus B-30892 caninhibit cytotoxic effects and adhesion of pathogenic Clostridium difficile to Caco-2 cells. Gut Pathog 2009;1:8.

47. Beighton D. The complex oral microflora of high-risk individuals and groups and its role in the caries process. Community Dent Oral Epidemiol 2005;33:248-55.

48. Belli WA, Marquis RE. Adaptation of Streptococcus mutans and Enterococcus hirae to acidstress in continuous culture. Appl Environ Microbiol 1991;57:1134-8.

49. Bernardeau M, Venoux JP, Henri-Dubernet S, Gueguen M. Safety assessment of dairy microorganisms: the Lactobacillus genus. Int J Food Microbiol 2008;126:278-85.

50. Cosseau C, Devine DA, Dullaghan E, et al. The commensal Streptococcus salivarius K12 downregulates the innate immune responses of human epithelial cells and promotes host-microbe homeostasis. Infect. Immun 2008;76:4163-75.

51. Bury RG, Tudehope D. Enteral antibiotics for preventing necrotizing enterocolitis in low birthweight or preterm infants [review]. Cochrane Database Syst Rev. 2001;CD000405.

52. Wehkamp J, Harder J, Wehkamp K, et al. NF-kappaB- and AP-1- mediated induction of human beta defensin-2 in intestinal epithelial cells by Escherichia coli Nissle 1917: a novel effect of a probiotic bacterium. Infect Immun 2004;72:5750-8.

53. Kalliomaki MA, Isolauri E. Probiotics and down-regulation of the allergic response. Immunolgy Allergy Clin North Am 2004;24: 739-52.

54. Viljanen M, Savilahti E, Haahtela T, et al. Probiotics in the treatment of atopic eczema/dermatitis syndrome in infants: a double-blind placebo-controlled trial. Allergy 2005;60:494-500.

55. Pouchard P, Gosset P, Grangette C, et al. Lactic acid bacteria inhibit TH2 cytokine production by mononuclear cells from allergic patients. J Allergy Clin Immunol 2002;110:617-23.

56. Rosenfeldt V, Benfeldt E, Valerius NH, et al. Effect of probiotics on gastrointestinal symptoms and small intestinal permeability in children with atopic dermatitis. J Pediatr 2004;145:612-6.

57. Mastrandrea F, Coradduzza G, Sero G, et al. Probiotics reduce the CD34+ hemopoietic precursor cell increased traffic in allergic subjects. Allerg Immunol 2004;36:118-22.

58. Nanthakumar NN, Young C, Ko JS, et al. Glucocorticoid responsiveness in the developing human intestine: possible role in the prevention of necrotizing enterocolitis. Am J Physiol Gastrointest Liver Physiol 2005;288:G85-92.

59. Braat $H$, van den Brande J, van Tol E, et al. Lactobacillus rhamnosus induces peripheral hyporesponsiveness in stimulated CD4+ T cells via modulation of dendritic cell function. Am J Clin Nutr 2004; 80:1618-25.

60. Shi HN, Walker WA. Bacterial colonization and the development of intestinal defenses. Can J Gastroenterol 2004;18:493-500.

61. Kawai T, Akira S. TLR signaling. Cell Death Differ 2006; 13:816-25.

62. Kerneis S, Bogdanova A, Kraehenbuhl JP, Pringault E. Conversion by Peyer's patch lymphocytes of human enterocytes into $\mathrm{M}$ cells that transport bacteria. Science 1997;277:910-1.

63. Macpherson AJS, Lamarre A, McCoy K, et al. IgA production without $\mathrm{m}$ or $\mathrm{d}$ chain expression in developing B cells. Nat Immunol 2001;2:625-31.

64. .Qamar A, Aboudola A, Warny M, et al. Saccharomyces boulardii stimulates intestinal immunoglobulin A immune response to Clostridium difficile toxin $\mathrm{A}$ in mice. Infect Immun 2001;69:2762-5.

65. Mack DR, Michail S, Wei S, et al. Probiotics inhibit enteropathogenic E. coli adherence in vitro by inducing intestinal mucin gene expression. Am J Physiol 1999;276:G941-50.

66. Bashir MEH, Andersen P, Fuss IJ, et al. An enteric helminth infection protects against an allergic response to dietary antigen. J Immunol. 2002;169:3284-92.

67. Bashir MEH, Louie S, Shi HN, NaglerAnderson C. Toll-like receptor 4 signaling by intestinal microbes influences susceptibility to food allergy. J Immunol 2004;172: 6978-87.

68. Braat H, van den Brande J, van Tol E, et al. Lactobacillus rhamnosus induces peripheral hyporesponsiveness in stimulated CD4+ T cells via modulation of dendritic cell function. Am J Clin Nutr 2004;80:161825.

69. Lin HC, Su BH, Chen AC, et al. Oral probiotics reduce the incidence and severity of necrotizing enterocolitis in very low birth weight infants. Pediatrics 2005;115:1-4.

70. Deshpande G, Rao S, Patole S. Probiotics for prevention of necrotizing enterocolitis in preterm neonates with very low birthweight: a systematic review of randomized controlled trials. Lancet 2007;369:1614-20.

71. Claud EC, Lu L, Anton PM, et al. Developmentally-regulated IkB expression in intestinal epithelium and susceptibility to flagellin-induced inflammation. Proc Natl Acad Sci U S A 2004;101:7404-8.

72. Bodet C, Chandad F, Grenier D. Modulation of cytokine production by Porphyromonas gingivalis in a macrophage and epithelial cell co-culture model. Microbes Infect 2005;7:448-56.

73. Bodet C, Andrian E, Tanabe S, Grenier D. Actinobacillus actinomycetemcomitans lipopolysaccharide regulates matrix metalloproteinase, tissue inhibitors of matrix 
metalloproteinase, and plasminogen activator production by human gingival fibroblasts: a potential role in connective tissue destruction. J Cell Physiol 2007;212:18994.

74. Boekhorst J, Wels M, Kleerebzem M, Siezen RJ. The predicted secretome of Lactobacillus plantarum WCFS1 sheds light on interactions with its environment. Microbiology 2006;152:3175-83.

75. Borrell LN, Papapanou PN. Analytical epidemiology of periodontitis. J Clin Periodontol 2005;32:132-58.

76. Bosch JA, Turkenburg M, Nazmi K, et al. Stressas a determinant of saliva-mediated adherence and coadherence of oral and nonoral microorganisms. Psychosom Med 2003;65:604-12.

77. Braat H, Rottiers P, Hommes DW, et al. A phase I trial with transgenic bacteria expressingInterleukin-10 in Crohn's disease. Clin Gastroenterol Hepatol 2006;4: 754-9.

78. Burton JP, Chilcott CN, Moore CJ, et al. A preliminary study of the effect ofprobiotic Streptococcus salivarius K12 on oral malodour parameters. J Appl Microbiol 2006;100:754-64.

79. Cabrera CC, Hakeberg M, Ahlqwist M, et al. Can the relation between tooth loss and chronic disease be explained by socio-economic status? A 24 year follow-up from the population study of women in Gothenburg, Sweden. Eur J Epidemiol 2005;20:229-36.

80. Çaglar E, Kargul B, Tanboga I. Bacteriotherpay and probiotics' role on oral health. Oral Dis 2005;11:131-7.

81. Çaglar E, Cildir SK, Ergeneli S, et al. Salivary mutans streptococci and lactobacilli levels after ingestion of the probiotic bacterium Lactobacillus reuteri ATCC 55730 by straws or tablets. Acta Odontol Scand 2006;64:314-8.

82. Çaglar E, Kavaloglu SC, Kuscu 00, et al. Effect of chewinggums containing xylitol or probiotic bacteria on salivary mutans streptococci and lactobacilli. Clin Oral Investig 2007;11:425-9.

83. Çaglar E, Kusku 00, Cildir SK, et al. A probiotic lozenge administered medical device and its effect on salivary mutans streptococci and lactobacilli. Int J Paediatr Dent 2008;18:35-9.

84. Çaglar E, Sandalli N, Twetman S, et al. Effect of yogurt withBifidobacterium DN173010 on salivary mutans streptococci and lactobacilli in young adults. Acta Odontol Scand 2005;63:317-20.

85. Salminen MK, Tynkkynen S, Rautelin H, et al. Lactobacillus bacteremia during a rapid increase in probiotic use of Lactobacillus rhamnosus GG in Finland. Clin Infect Dis 2002;35:1155-60.

86. Calkins CC, Platt K, Potempa J, Travis J.
Inactivation of tumor necrosis factor-alpha by proteinases (ginigipains) from the periodontal pathogen, Porphyromonas gingivalis. Implications of immune evasion. J Biol Chem 1998;273:6611-4.

87. Carbo ML, Braber AF, Koenraad PM. Apparent antifungal activity of cervical lactic acid bacteria against Penicillinum discolor is due to acetic acid in the medium. J Food Prot 2002;65:1309-16.

88. Saavedra JM, Abi-Hanna A, Moore N, Yolken RH. Long-term consumption of infant formulas containing live probiotic bacteria: tolerance and safety. Am J Clin Nutr 2004;79:261-7.

89. Carvalho JC, Figueiredo MJ, Vieira E0, Mestrinho HD. Caries trends in Brazilian nonprivileged preschool children in 1996 and 2006. Caries Res 2009;43:2-9.

90. Caufield PW. Dental caries: an infectious and transmissible disease where have we been andwhere are we going? N Y State Dent J 2005;71:23-7.

91. Cildir SK, Germec D, Sandalli N, et al. Reduction of salivary mutans streptococci in orthodontic patients during daily consumption of yoghurt containing probiotic bacteria. Eur J Orthod 2009; 31:407-411.

92. Coeuret V, Gueguen M, Vernoux JD. In vitro screening of potential probiotic activities of selected lactobacilli isolated from unpasteurized milk products for incorporation into soft cheese. J Dairy Res 2004; 71:451-60.

93. Çaglar E, Kavaloglu SC, Kuscu 00, et al. Effect of chewing gums containing xylitol or probiotic bacteria on salivary mutans streptococci and lactobacilli. Clin Oral Investig 2007;11:425-9.

94. Çaglar E, Kusku 00, Cildir SK, et al. A probiotic lozenge administered medical device and its effect on salivary mutans streptococci and lactobacilli. Int J Paediatr Det 2008;18:35-9.

95. Cildir SK, Germec D, Sandalli N, et al. Reduction ofsalivary mutans streptococci in orthodontic patients during daily consumption of yoghurt containing. probiotic bacteria. Eur J Orthod 2009; 31:407-11.

96. Hunter CJ, Williams M, Petrosyan M, et al. Lactobacillus bulgaricus prevents intestinal epithelial cell injury caused by Enterobacter sakazakii-induced nitric oxide both in vitro and in the newborn rat model of necrotizing enterocolitis. Infect Immun 2009;77:1031-43.

97. Mantzourani M, Gilbert SC, Sulong HNH, et al. The isolation of bifidobacteria from occlusal carious lesions in children and adults. Caries Res 2009;43:308-13.

98. Teran CG, Teran-Escalera CN, Villarroel P. Nitazoxanide vs. probiotics for the treatment of acute rotavirus diarrhea in children: a randomized, single-blind, con- trolled trial in Bolivian children. Int $\mathrm{J}$ Infect Dis 2009;13:518-23.

99. Vieira LQ, dos Santos LM, Neuman E, et al. Probiotics protectmice against experimental infections. J Clin Gastroenterol 2008; 42:168-9.

100.Wada M, Nagata S, Saito M, et al. Effects of the enteral administration of Bifidobacterium breve on patients undergoing chemotherapy for pediatric malignancies. Support Care Cancer 2010;18: 751-9.

101.Christensen HR, Frokiaer H, Pestka JJ. Lactobacilli differentially modulate expression of cytokines and maturation surface markers in murine dendritic cells. J Immunol 2002;168:171-8.

102.Cadieux P, Burton J, Gardiner G, et al. Lactobacillus strains and vaginal ecology. JAMA 2002;287:1940-1.

103.Kalliomaki M, Salminen S, Arvilommi H, et al. Probiotics in primary prevention of atopic disease: a randomized placebo-controlled trial. Lancet 2001;357:1076-9.

104.Nase L, Hatakka K, Savilahti E, et al. Effect of long-term consumption of a probiotic bacterium, Lactobacillus rhamnosus GG, in milk on dental caries and caries risk in children. Caries Res 2001;35:412-20.

105.Vanderhoof JA. Probiotics: future directions. Am J Clin Nutr 2001;73:1152S$1155 \mathrm{~S}$.

106.Weizman Z, Asli G, Alsheikh A. Effect of a probiotic infant formula on infections in child care centers: comparison of two probiotic agents. Pediatrics 2005;115:5-9.

107. Rio ME, Zago Beatriz L, Garcia H, Winter L. The nutritional status change the effectiveness of a dietary supplement of lactic bacteria on the emerging of respiratory tract diseases in children. Arch Latinoam Nutr 2002;52:29-34. [Article in Spanish].

108.Hatakka K, Savilahti E, Ponka A, et al. Effect of long term consumption of probiotic milk on infections in children attending day care centres: double blind, randomised trial. BMJ 2001;322:1327.

109.Salminen MK, Tynkkynen S, Rautelin H, et al. Lactobacillus bacteremia during a rapid increase in probiotic use of Lactobacillus rhamnosus GG in Finland. Clin Infect Dis 2002;35:1155-60.

110.Saikali J, Picard C, Freitas M, Holt P. Fermented milks, probiotic cultures, and colon cancer. Nutr Cancer 2004;49:14-24.

111.Rescigno M, Urbano M, Valzasina B, et al. Dendritic cells express tight junction proteins and penetrate gut epithelial monolayers to sample bacteria. Nat Immunol 2001;2:361-7.

112.Macpherson AJ, Uhr T. Induction of protective IgA by intestinal dendritic cells carrying commensal bacteria. Science 2004; 303:1662-5. 
113.Rachmilewitz D, Katakara K, Karmeli F, et al. Toll-like receptor 9 signaling mediates the anti-inflammatory effects of probiotics in murine experimental colitis. Gastroenterology 2004;126:520-8.

114.Neish AS, Gewirtz AT, Zeng H, et al. Prokaryotic regulation of epithelial responses by inhibition of IkBa degradation. Science 2000; 289:1560-3.

115.0tte JM, Podolsky DK. Functional modulation of enterocytes by grampositive and gram-negative microorganisms. Am J Physiol Gastrointest Liver Physiol 2004;286: G613-26.

116.Kalliomaki MA, Walker WA. Physiologic and pathologic interactions of bacteria with gastrointestinal epithelium. Gastroenterol Clin North Am 2005;34:383-99.

117.0tten CM, Kok L, Witteman BJ, et al. Diagnostic performance of rapid tests for detection of fecal calprotectin and lactoferrin and their ability to discriminate inflammatory from irritable bowel syndrome. Clin Chem Lab Med 2008;46:127580.

118.Valicenti-McDermott M, McVicar K, Rapin I, et al. Frequency of gastrointestinal symptoms in children with autistic spectrum disorders and association with family history of autoimmune disease. J Dev Behav Pediatr 2006;27Suppl2:S128-36.

119.MacFabe DF, Cain DP, Rodriguez-Capote K, et al. Neurobiological effects of intraventricular propionic acid in rats: Possible role of short chain fatty acids on the pathogenesis and characteristics of autism spectrum disorders. Behav Brain Res 2007;176:149-69.

120.Cosseau C, Devine DA, Dullaghan E, et al. The commensal Streptococcus salivarius K12 downregulates the innate immune responses of human epithelial cells and promotes host-microbe homeostasis. Infect Immun 2008;76:4163-75.

121.Gu Y, Lee HM, Sorsa T, et al Doxycyline inhibits mononuclear cell-mediated connective tissue breakdown. FEMS Immunol Med Microbiol 2010;58:218-25.

122.Selvam R, Maheswari P, Kavitha P, et al. Effect of Bacillus subtilis PB6, a natural probiotic on colon mucosal inflammation and plasma cytokines levels in inflammatory bowel disease. Indian $\mathrm{J}$ Biochem Biophys 2009;46:79-85.

123.Silva N, Dutzan N, Hernandez M, et al. Characterization of progressive periodontal lesions in chronic periodontitis patients: levels of chemokines, cytokines, matrix metalloproteinase-13, periodontal pathogens and inflammatory cells. J Clin Periodontol 2008;35:206-14.

124.Snydman DR. The safety of probiotics. Clin Infect Dis 2008;46:104-11.

125.Parra MD, Martinez de Morentin BE, Cobo
JM, et al. Daily ingestion of fermented milk containing Lactobacillus casei DN114001 improves innate-defense capacity in healthy middle-aged people. J Physiol Biochem 2004;60:85-91.

126.Pohjavuori E, Viljanen M, Korpela R, et al. Lactobacillus GG effect in increasing IFNgamma production in infants with cow's milk allergy. J Allergy Clin Immunol, 2004;114:131-6.

127.Szajewska H, Mrukowicz JZ. Probiotics in the treatment and prevention of acute infectious diarrhea in infants and children: a systematic review of published randomized, double-blind, placebo-controlled trials. J Pediatr Gastroenterol Nutr 2001;33Suppl2:S17-25.

128.Sazawal S, Hiremath G, Dhingra U, et al. Efficacy of probiotics in prevention of acute diarrhoea: a meta-analysis of masked, randomised, placebo-controlled trials. Lancet Infect Dis 2006;6:374-82.

129.Van Niel CW, Feudtner C, Garrison MM, Christakis DA. Lactobacillus therapy for acute infectious diarrhea in children: a meta-analysis. Pediatrics 2002;109:678-84.

130.Allen SJ, Okoko B, Martinez E, et al. Probiotics for treating infectious diarrhoea. Cochrane Database Syst Rev 2004: CD003048.

131.American Academy of Pediatrics. Statement of endorsement: managing acute gastroenteritis among children: oral rehydration, maintenance, and nutritional therapy. Pediatrics 2004;114:507.

132.Bender BJ, Ozuah PO, Crain EF. Oral rehydration therapy: is anyone drinking? Pediatric Emerg Care 2007;23:624-6.

133.0zuah P0, Avner JR, Stein RE. Oral rehydration, emergency physicians, and practice parameters: a national survey. Pediatrics 2002; 109:259-61.

134.Conners GP, Barker WH, Mushlin AI, Goepp JG. Oral versus intravenous: rehydration preferences of pediatric emergency medicine fellowship directors. Pediatr Emerg Care 2000;16:335-8.

135.Atherly-John YC, Cunningham SJ, Crain EF. A randomized trial of oral vs intravenous rehydration in a pediatric emergency department. Arch Pediatr Adolesc Med 2002;156:1240-3.

136. Hungin AP, Chang L, Locke GR, et al. Irritable bowel syndrome in the United States: prevalence, symptom patterns and impact. Aliment Pharamacol Ther 2005;21: 1365-75.

137.El-Serag HB, Olden K, Bjorkaman D. Health-related quality of life among persons with irritable bowel syndrome: a systematic review. Aliment Pharmacol Ther 2002;16:1171-85.

138.Spigel BM. The burden of IBS: looking at metrics. Curr Gastroenterol Rep 2009;11:
265-9.

139.Maxion-Bergemann S, Thielecke F, Abel F, et al. Costs of irritable bowel syndrome in the UK and US. Pharmacoeconomics 2006;24:21-37.

140.Ringel Y, Drossman DA. Irritable bowel syndrome. In: Runge MS, Greganti MA. Netter's Textbook of Internal Medicine. 2nd edition. Philadelphia: Saunders Elsevier; 2008: 59:419-25.

141.Brandt LJ, Chey WD, Foxx-Orenstein AE, et al. American College of Gastroenterology task force on irritable bowel syndrome: an evidence-based position statement on the management of irritable bowel syndrome. Am J Gastroenterol 2009;104Suppl1:S1S35.

142.Ringel Y, Carroll I. Alternations of intestinal microbiota and functional bowel symptoms: in gastrointestinal motility and neurogastroenterology. Gastrointest Endosc Clin N Am 2009;19:141-50.

143.Arebi N, Gurmany S, Bullas D, et al. Review article: the psychoneuroimmunology of irritable bowel syndrome-an exploration of interactions between psychological, neurological and immunological observations. Aliment Pharmacol Ther 2008;28:830-40.

144.Brenner DM, Moeller MJ, Chey WD, et al. The utility of probiotics in the treatment of irritable bowel syndrome: a systematic review. Am J Gastroenterol 2009;104:103349.

145.Pimentel M, Park S, Mirocha J, et al. The effect of nonabsorbed oral antibiotic (rifamixin) on the symptoms of the irritable bowel syndrome: a randomized trial. Ann Intern Med 2006;145:557-63.

146.Sharara AI, Aoun E, Abdul-Baki H, et al. A randomized double-blind placebo-controlled trial of rifamixin in patients with abdominal bloating and flatulence. Am J Gastroenterol 2006;101:326-33.

147.Pimentel M, Lembo A, Chey WD, et al. TARGET Study Group. Rifaximin therapy for patients with irritable bowel syndrome without constipation. N Engl J Med 2011; 364:22-32.

148.de Vrese M, Stegelmann A, Richter B, et al. Probiotics-compensation for lactase insufficiency. Am J Clin Nutr 2001;73:421S-9S.

149.Marteau P, Flourié B, Pochart P, et al. Effect of the microbial lactase activity in yogurt on the intestinal absorption of lactose: an in vivo study in lactase-deficient humans. Br J Nutr 1990;64:71-9.

150.Mahé S, Marteau $P$, Huneau JF, et al. Intestinal nitrogen and electrolyte movements following fermented milk ingestion in human. Br J Nutr 1994;71:169-80.

151.Lin M, Yen CL, Chen SH. Management of lactose maldigestion by consuming milk 
containing lactobacilli. Dig Dis Sci 1998;43:133-7.

152.Arrigoni E, Marteau P, Briet F, et al. Tolerance and absorption of lactose from milk and yogurt during short-bowel syndrome in humans. Am $\mathrm{J}$ Clin Nutr 1994;60:926-9.

153. Marteau P, Messing B, Arrigoni E, et al. Do patients with short bowel syndrome need a lactose free diet? Nutrition 1997;13:13-6.

154.Harms HK, Bertele-Harms RM, Bruer-Kleis D. Enzyme substitution therapy with the yeast Saccharomyces cerevisiae in congenital sucrase-isomaltase deficiency. $\mathrm{N}$ Engl J Med 1987;316:1306-9.

155.Bamford CV, d'Mello A, Nobbs AH, et al. Streptococcus gordonii modulates Candida albicans biofilm formation through intergeneric communication. Infect. Immun 2009;77:3696-704.

156.Banbula A, Bugno M, Kuster A, et al. Rapid and efficient inactivation of IL- 6 gingipains, lysine- and arginine-specific proteinases from Porphyromonas gingivalis. Biochem Biophys Res Commun 1999;261: 598-602.

157.Banerjee P, Merkel GJ, Bhunia AK. Lactobacillus delbrueckii ssp. bulgaricus B-30892 caninhibit cytotoxic effects and adhesion of pathogenic Clostridium difficile to Caco-2 cells. Gut Pathog 2009;1:8.

158.Beighton D. The complex oral microflora of high-risk individuals and groups and its role in the caries process. Community Dent Oral Epidemiol 2005;33:248-55.

159.Belli WA, Marquis RE. Adaptation of Streptococcus mutans and Enterococcus hirae to acidstress in continuous culture. Appl Environ Microbiol 1991;57:1134-8.

160.Bernardeau M, Venoux JP, Henri-Dubernet $\mathrm{S}$, Gueguen M. Safety assessment of dairy microorganisms: the Lactobacillus genus. Int J Food Microbiol 2008;126:278-85.

161.Cosseau C, Devine DA, Dullaghan E, et al. The commensal Streptococcus salivarius K12 downregulates the innate immune responses of human epithelial cells and promotes host-microbe homeostasis. Infect Immun 2008;76:4163-75.

162.Bury RG, Tudehope D. Enteral antibiotics for preventing necrotizing enterocolitis in low birthweight or preterm infants [review]. Cochrane Database Syst Rev. 2001;CD000405.

163.Cremonini F, Di Caro S, Nista EC, et al. Meta-analysis: the effect of probiotic administration on antibiotic-associated diarrhoea. Aliment Pharmacol Ther 2002;16:1461-7.

164.Dillman DA. Mail and internet surveys: the tailored design method. 2nd ed. Hoboken, NJ: John Wiley \& Sons; 2000.

165.Ringel Y, Zakko S, Ferreira N, et al. Predictors of clinical response from a phase 2 multi-center efficacy trial using rifaximin, a gut-selective, nonabsorbed antibiotic for the treatment of diarrheaassociated irritable bowel syndrome. Gastroenterology 2008;134suppl1:A550.

166.Aas JA, Griffen AL, Dardis SR, et al. Bacteria of dental caries in primary and permanent teeth in children and young adults. J Clin Microbiol 2008;46:1407-17.

167.Kaur PI, Chopra K, Saini A. Probiotics: potential pharmaceutical applications. Eur J Pharm Sci 2002;15:1-9.

168.Fujimori S, Gudis K, Mitsui K, et al. A randomized controlled trial on the efficacy of synbiotic versus probiotic or prebiotic treatment to improve the quality of life in patients with ulcerative colitis. Nutrition 2009;25:520-5.

169.Guill HS, Gaumer F. Probiotics and human health: a clinical perspective. J Post Grad Med 2004;80:516-6.

170.Miele E, Pascarella F, Giannetti E, et al. Effect of a probiotic preparation (VSL 3) on induction and maintenance of remission in children with ulcerative colitis. Am J Gastroenterol 2009;104:437-43.

171.Sood A, Midha V, Makharia GK, et al. The probiotic preparation, VSL 3 induces remission in patients with mild-to-moderately active ulcerative colitis. Clin Gastroenterol Hepatol 2009;7:1202-9.

172.Rembacken BJ, Snelling AM, Hawkey PH, et al. Non-pathogenic Escherichia coli versus mesalazine for the treatment of ulcerative colitis: a randomized trial. Lancet 1999;354:635-9.

173.Fedorak RN, Dieleman LA. Probiotics in the treatment of human inflammatory bowel diseases: update 2008. J Clin Gastroenterol 2008;42:S97-103.

174. Floch MH, Walker WA, Guandalini S, et al. Recommendations for probiotic use 2008. J Clin Gastroenterol 2008;42:S104-8.

175.Allen SJ, Okoko B, Martinez E, et al. Probiotics for treating infectious diarrhea. Cochrane Database Syst Rev 2003;2: CD003048.

176. Malchow HA. Crohn's disease and Escherichia coli: a new approach in therapy to maintain remission of colonic Crohn's disease? J Clin Gastroenterol 1997;25:653-8.

177.Guslandi M, Mezzi G, Sorghi M, Testoni PA. Saccharomyces boulardii in maintenance treatment of Crohn's disease. Dig Dis Sci 2000;45:1462-4.

178.Gupta P, Andrew H, Kirschner BS, Guandalini S. Is Lactobacillus GG helpful in children with Crohn's disease? Results of a preliminary, open-label study. J Pediatr Gastroenterol Nutr 2000;31:453-7,.

179.Campieri M, Rizzello F, Venturi A, et al. Combination of antibiotic and probiotic treatment is efficacious in prophylaxis of post-operative recurrence of Crohn's disease: a randomized controlled study v. mesalazine. Gastroenterology 2000;118: A4179.

180.Itoh J, de la Motte C, Strong SA, et al. Decreased Bax expression by mucosal $\mathrm{T}$ cells favours resistance to apoptosis in Crohn's disease. Gut 2001,49:35-41.

181.Guslandi M, Mezzi G, Sorghi M, Testoni PA. Saccharomyces boulardii in maintenance treatment of Crohn's disease. Dig Dis Sci 2000;45:1462-4.

182.Malin M, Suomalainen H, Saxelin M, Isolauri E. Promotion of IgA immune response in patients with Crohn's disease by oral bacteriotherapy with Lactobacillus GG. Ann Nutr Metab 1996;40:137-45.

183.Gupta P, Andrew H, Kirschner BS, Guandalini S. Is Lactobacillus GG helpful in children with Crohn's disease? Results of a preliminary, open-label study. J Pediatr Gastroenterol Nutr 2000;31:453-7.

184.Gionchetti P, Amadini C, Rizzello F, et al. Probiotics for the treatment of postoperativecomplications following intestinal surgery. Best Pract Res Clin Gastroenterol 2003;17:821-31,.

185.0'Mahony L, Mccarthy J, Kelly P, et al. Lactobacillus and Bifidobacterium in irritable bowel syndrome: symptom responses and relationship to cytokine profiles. Gastroenterol 2005;128:541-51.

186.Flynn S, van Sinderen D, Thornton GM, et al. Characterization of the genetic locus responsible for the production of ABP-118, a novel bacteriocin produced by the probiotic bacterium Lactobacillus salivarius subsp. salivarius UCC118. Microbiology 2002;148:973-84,

187.Bittner AC, Croffut RM, Stranahan MC, Yokelson TN. Prescript-assist probioticprebiotic treatment for irritable bowel syndrome: an open-label, partially controlled, 1-year extension of a previously published controlled clinical trial. Clin Ther, 2007;29:1153-60,

188.Bausserman M, Michail S. The use of Lactobacillus GG in irritable bowel syndrome in children: a double-blind randomized control trial. J Pediatr 2005;147:197201.

189.Niedzielin K, Kordecki H, Birkenfeld B. A controlled, doubleblind, randomized study on the efficacy of Lactobacillus plantarum $299 \mathrm{~V}$ in patients with irritable bowel syndrome. Eur J Gastroenterol Hepatol 2001; 13:1143-7.

190.0'Sullivan MA, 0’Morain CA. Bacterial supplementation in the irritable bowel syndrome. A randomised double-blind placebocontrolledcrossover study. Dig Liver Dis 2000;32:294-301.

191.Saggioro A. Probiotics in the treatment of irritable bowel syndrome. J Clin Gastro- 
enterol 2004;38:S104-6.

192.Mimura T, Rizzello F, Helwig U, et al. Once daily high dose probiotic therapy (VSL\#3) for maintaining remission in recurrent or refractory pouchitis. Gut 2004;53:108-14.

193.Gionchetti P, Rizzello F, Helwig U, et al. Prophylaxis of pouchitis onset with probiotic therapy: a double-blind, placebo-controlled trial. Gastroenterology 2003;124: 1202-9.

194.Kuehbacher T, Ott SJ, Helwig U, et al. Bacterial and fungal microbiota in relation to probiotic therapy (VSL\#3) in pouchitis. Gut 2006;55:833-41.

195. Kuisma J, Mentula S, Jarvinen H, et al. Effect of Lactobacillus rhamnosus GG on ileal pouch inflammation and microbial flora. Aliment Pharmacol Ther 2003;17: 509-15.

196. Rembacken BJ, Snelling AM, Hawkey PM, et al. Non-pathogenic Escherichia coli versus mesalazine for the treatment of ulcerative colitis: a randomized trial. Lancet 1999;354:635-9.

197.Kruis W, Fric P, Pokrotnieks J,et al. Maintaining remission of ulcerative colitis with the probiotic Escherichia coli Nissle 1917 is as effective as with standard mesalazine Gut, 2004;53:1617-23,.

198.Tursi A, Brandimarte G, Giorgetti GM, et al. Low-dose balsalazide plus a high-potency probiotic preparation is more effective than balsalazide alone or mesalazine in the treatment of acute mild-to-moderate ulcerative colitis. Med Sci Monit 2004;10: PI126-31.

199.Karimi 0, Peña AS, van Bodegraven AA. Probiotics (VSL\#3) in arthralgia in patients with ulcerative colitis and Crohn's disease: a pilot study. Drugs Today (Barc) 2005;41:453-9.

200.Furrie E, Macfarlane S, Kennedy A, et al. Synbiotic therapy (Bifidobacterium longum/Synergy 1) initiates resolution of inflammation in patients with active ulcerative colitis: a randomised controlled pilot trial. Gut 2005;54:242-9.

201.Cui HH, Chen CL, Wang JD, et al. Effects of probiotic on intestinal mucosa of patients with ulcerative colitis. World $\mathrm{J}$
Gastroenterol 2004;10:1521-5.

202.Carroll LM, Andrus JM, Bruno-B’arcena $\mathrm{JM}$, et al. Antiinflammatory properties of Lactobacillus gasseri expressing manganese superoxide dismutase using the interleukin 10- deficient mouse model of colitis. Am J Physiol 2007;293:G729-38.

203.Peran L, Sierra S, Comalada M, et al. A comparative study of the preventative effects exerted by two probiotics, Lactobacillus reuteri and Lactobacillus fermentum, in the trinitrobenzenesulfonic acid model of rat colitis. Br J Nutr 2007; 97:96-103.

204. Matsumoto S, Hara T, Hori T, et al. Probiotic Lactobacillus-induced improvement in murine chronic inflammatory bowel disease is associated with the downregulation of pro-inflammatory cytokines in lamina propria mononuclear cells. Clin Exp Immunol 2005;140:417-426.

205.Carol, N. Borruel M, Antolin M, et al. Modulation of apoptosis in intestinal lymphocytes by a probiotic bacteria in Crohn's disease. J Leukoc Biol 2006;79:917-22.

206.Schultz M, Veltkamp C, Dieleman LA, et al. Lactobacillus plantarum $299 \mathrm{~V}$ in the treatment and prevention of spontaneous colitis in interleukin-10-deficient mice. Inflamm Bowel Dis 2002;8:71-80.

207. Peña JA, Versalovic J. Lactobacillus rhamnosus GG decreases TNF- production in lipopolysaccharide-activated murine macrophages by a contact-independent mechanism. Cell Microbiol 2003;5:277-85,.

208. Majamaa H, Isolauri E. Probiotics: a novel approach in the management of food allergy. J Allergy Clin Immunol 1997;99:179-85, .

209.Sheil B, McCarthy J, O'Mahony L, et al. Is the mucosal route of administration essential for probiotic function? Subcutaneous administration is associated with attenuation of murine colitis and arthritis Gut 2004;53:694-700.

210.0'Mahony L, Feeney M, 0'Halloran S, et al. Probiotic impact on microbial flora, inflammation and tumour development in IL-10 knockout mice. Aliment Pharmacol
Therap 2001;15:1219-25.

211.Flynn S, van Sinderen D, Thornton GM, et al. Characterization of the genetic locus responsible for the production of ABP-118, a novel bacteriocin produced by the probiotic bacterium Lactobacillus salivarius subsp. salivarius UCC118. Microbiology 2001;148:973-84.

212.Madsen KL, Doyle JS, Jewell LD, et al. Lactobacillus species prevents colitis in interleukin 10 gene-deficient mice. Gastroenterology 1999;116:1107-14.

213.Gionchetti P, Rizzello F, Helwig U, et al. Prophylaxis of pouchitis onset with probiotic therapy: a double-blind, placebo-controlled trial. Gastroenterology 2003;124: 1202-9.

214.Venturi A, Gionchetti P, Rizzello F, et al. Impact on the composition of the faecal flora by a new probiotic preparation: preliminary data on maintenance treatment of patients with ulcerative colitis. Aliment Pharmacol Therap, 1999;13:1103-8.

215.van Embden JGHR, Schouten WR, Van Lieshout LMC. Pouchitis: result of microbial imbalance? Gut 1994;35:658-64.

216.Gionchetti P, Amadini C, Rizzello F, et al. Probiotics for the treatment of postoperativecomplications following intestinal surgery. Best Pract Res Clin Gastroenterol 2003;17:821-31.

217.Kajander K, Korpela R. Clinical studies on alleviating the symptoms of irritable bowel syndrome with a probiotic combination. Asia Pac J Clin Nutr 2006;15:576-80.

218.0sman N, Adawi D, Ahrne S, et al. Modulation of the effect of dextran sulfate sodium-induced acute colitis by the administration of different probiotic strains of Lactobacillus and Bifidobacterium. Dig Dis Sci 2004;49:320-7.

219.Gupta P, Andrew H, Kirschner BS, Guandalini S. Is Lactobacillus GG helpful in children with Crohn's disease? Results of a preliminary, open-label study J Pediatr Gastroenterol Nutr 2003;31:453-7. 